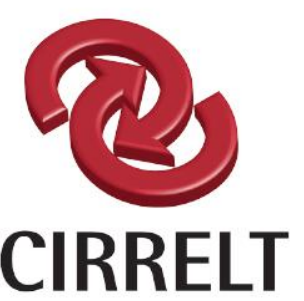

Centre interuniversitaire de recherche sur les réseaux d'entreprise, la logistique et le transport Interuniversity Research Centre

on Enterprise Networks, Logistics and Transportation

\title{
From Managing Urban Freight to Smart City Logistics Networks
}

\author{
Tolga Bektaș \\ Teodor Gabriel Crainic \\ Tom Van Woensel
}

May 2015

CIRRELT-2015-17

Bureaux de Montréal : Université de Montréal

Pavillon André-Aisenstadt

C.P. 6128, succursale Centre-ville

Montréal (Québec)

Canada $\mathrm{H} 3 \mathrm{C} 3 \mathrm{~J} 7$

Téléphone : 514 343-7575

Télécopie : 514 343-7121

www.cirrelt.ca
Bureaux de Québec :

Université Laval

Pavillon Palasis-Prince

2325, de la Terrasse, bureau 2642

Québec (Québec)

Canada GIV 0 A6

Téléphone : 418 656-2073

Télécopie : 418 656-2624 


\section{From Managing Urban Freight to Smart City Logistics Networks}

\section{Tolga Bektaș ${ }^{1}$, Teodor Gabriel Crainic ${ }^{2,3,}$, , Tom Van Woensel ${ }^{4}$}

${ }^{1}$ School of Management,Centre for Operational Research, Management Science and Information systems (CORMSIS), University of Southampton, Southampton, SO17 1BJ, United Kingdom

2 Interuniversity Research Centre on Enterprise Networks, Logistics and Transportation (CIRRELT)

${ }^{3}$ Department of Management and Technology, Université du Québec à Montréal, P.O. Box 8888, Station Centre-Ville, Montréal, Canada H3C 3P8

${ }^{4}$ Eindhoven University of Technology, Eindhoven 5600 MB, The Netherlands

Abstract. We present City Logistics by taking a systemic view, describing its main components and elements, as an emerging field of study with wide and significant social and economic impact. We then review contributions and identify some of the challenges that City Logistics raises, particularly for Operations Research and Transportation Science. The focus is on the network design issues relative to the system structure and services.

Keywords: City Logistics, literature review, network design, system evaluation, system design, service.

Acknowledgements. Partial funding for this project has been provided by the Natural Sciences and Engineering Research Council of Canada (NSERC), through its Discovery Grants program. We also gratefully acknowledge the support of the Fonds de recherche du Québec - Nature et technologie (FRQNT) through their infrastructure grants.

Results and views expressed in this publication are the sole responsibility of the authors and do not necessarily reflect those of CIRRELT.

Les résultats et opinions contenus dans cette publication ne reflètent pas nécessairement la position du CIRRELT et n'engagent pas sa responsabilité.

\footnotetext{
* Corresponding author: TeodorGabriel.Crainic@cirrelt.ca

Dépôt légal - Bibliothèque et Archives nationales du Québec Bibliothèque et Archives Canada, 2015
}

(C) Bektaș, Crainic, Van Woensel and CIRRELT, 2015 


\section{Introduction}

Urban transportation involves the movement of both people and freight in urban areas. While the people-based transportation has developed reasonably well in the way of multi- and intermodal public transportation (e.g., buses, subways, taxis), particularly in large cities, this is not the case for freight. Urban freight transportation encompasses a significant amount of activities that take place within urban areas, with undesirable consequences on the environment, and subsequently on human health. The OECD (Organisation for Economic Co-operation and Development) Working Group on Urban Freight Logistics defines urban goods transport as "the delivery of goods in urban areas, including the reverse flow of waste". Taniguchi (2014) defines city logistics as "the process for totally optimizing the logistics and transport activities by private companies with support of advanced information systems in urban areas considering the traffic environment, the traffic congestion, the traffic safety and the energy savings within the framework of a market economy". There does not seem to be an unequivocal definition of city logistics although the emerging literature seems to be converging to the consensus the concept (i) explicitly refers to urban freight transportation, (ii) is based on the idea of running an integrated logistics system with consolidation and coordination lying at the heart, and (iii) aims to increase efficiency and reduce environmental damage. The definition of efficiency encompasses the use of fewer vehicles, better utilization of vehicle capacity (hence fewer empty trips) and reduction of fuel or energy, leading to reduced emissions of $\mathrm{CO}_{2}$ and other greenhouse gases. Efficiency also pertains to other parameters, such as flexibility of operations, service quality and synchronization of different services running in cities, albeit they are often much less straightforward to quantify as compared to the former set of parameters, but important enough to warrant consideration nevertheless. Substantial growth and new business models are expected following the increasing freight volumes due to the Internet shopping growth and improved mode utilisation (both in time and fill rate). New coordination mechanisms supported by ICT solutions leading to control towers, need to be designed to enable efficient integration. Additionally, price and sharing mechanisms have to be proposed. Summarising, cities are constantly involved in complex and multiple processes of change. An essential contribution to the economic grow and welfare of a urban ares comes from freight distribution. However, at the same time, freight transport also contributes to deterioriation of the quality of life in urban areas, as it is one of the major causes of traffic congestion, air pollution and noise. The attempt to be innovative and competitive while limiting the negative environmental impacts constitutes a fundamental dilemma of urban freight transportation (Ehmke, 2012). A natural conclusion that arises from these considerations is that the core of a sustainable growth of a city is to have a sustainable city logistics system.

Freight transportation of goods, (both forward flows and reverse flows) is therefore a key activity within urban areas. Many large cities face significant challenges related to the congestion and pollution generated by the number of vehicles which need to travel within urban areas. These vehicles are one of the main causes of undesired environmental side- 
effects but their role is fundamental to the efficient functioning of Europe as they satisfy many of the transportation needs that occur on a day-to-day basis. Urban transportation includes not only the transportation of goods, but a significant proportion is attributed to the transportation of people. Within the OECD countries, in 1950, 50\% of the population lived in cities, $77 \%$ in 2000 and it is expected that by 2020, this will rise to $85 \%$. Currently, $80 \%$ of the European population lives in urban areas, while about $85 \%$ of the EU's GDP is generated in cities. The demand for urban freight transport is clearly growing, and will continue to do so. In Europe, "transport is the most problematic emitting sector, with upward emission trends". Between 1990 and 2007, CO2 emissions from transport rose by $29 \%$ in Europe. Road transport accounts for a sizeable portion of CO2 transport related emissions, nearly $73 \%$ in 2000. Within road transport related CO2 emissions, urban traffic accounts for $40 \%$ of CO2 emissions, and $70 \%$ of emissions of other air pollutants. In terms of traffic congestion, in Europe, every year nearly 100 billion Euros, or 1\% of the EU's GDP, are lost to the European economy as a result of this phenomenon. The number of road traffic accidents in towns and cities is also growing each year: one in three fatal accidents happen in urban areas. In cities, large trucks and vulnerable road users (cyclists and pedestrians) share the same infrastructure. Furthermore, just over 41 million Europeans are exposed to excessive noise from road traffic alone in the largest European cities (European Environment Agency (EEA)). An important contemporary challenge for large cities is to improve the air quality: to satisfy the European norms for NOx, cities have to improve their air quality considerable. High concentrations of NOx and PM10 have negative consequences for the residents health. The majority of goods in urban areas are delivered via road haulage. It is startling to note that, on average, $24 \%$ of goods vehicles in Europe operate empty. Smaller vehicles have an average load capacity of only $57 \%$. Drastically reducing these inefficiencies is a major challenge for European policy-makers and private industries. A 30\% increase in efficiency would create an estimated economic value of 22 billion euro for the Transportation Industry. The private and public sector are increasingly challenged by these urban growth figures. This demonstrates the need for better control of urban freight transportation in order to reduce its impact on adverse living conditions in cities.

The demand for urban freight transport is clearly growing, and will continue to do so. Additionally, in developing economies, urbanisation is happening at a very fast pace, leading to mega-cities. As Blanco and Fransoo (2013) point out, there are multiple definitions of mega-cities around. From a logistics perspective, these authors propose to use the density, rather than the population size of the city. In a study published by City Mayors (2007), the most dense European cities (i.e., Athens, London, Madrid) have a density of about 5,000 people per square kilometer, while in the US, this is around 3,000 people or less per square kilometer (e.g., Los Angeles, New Orleans). However, compared to Mumbai (India) the average population density is about 30,000 people per square kilometer, while Beijing is around 11,500 people per square kilometer.

The objective of this chapter is twofold. First, we present City Logistics by taking 
a systematic view, describing its main components and elements, as emerging field of study with wide and significant social and economic impact. Second, we identify some of the challenges that City Logistics raises, particularly for Operations Research and Transportation Science. Given the scope of the book, the complexity of the topic, and the paper-length constraints, the focus of the content is on the network design issues relative to the system structure and services. The interested reader may consult a number of books (e.g., Taniguchi et al., 2001a; Patier, 2002; Ehmke, 2012; Gonzalez-Feliu et al. 2014) and the compendiums of papers out of the City Logistics International Conferences (http://citylogistics.org/).

The structure of the chapter is as follows. In Section 2, we provide a classification of the three main components of City Logistics as a system, which are discussed in greater detail in Section 3, 4 and 5, respectively. Section 6 discusses some new initiatives taken in City Logistics along with two novel concepts of great pratical and scientific interest.

\section{City Logistics: A Systematic View and Main Con- cepts}

City Logistics are transportation and logistics systems, meaning that they deploy infrastructure and service networks to move and, eventually, store freight on its way from origins to destinations. Designing and planning the operations of City Logistics systems therefore directly raises the need to design and evaluate physical and service networks, route vehicles of various modes, and determine how to best move freight using these services and vehicles. Clearly, City Logistics planning and operations do not take place in a vacuum as, on the one hand, it shares most of its transportation infrastructure with the movements of people by private and public means while, on the other hand, urban freight transportation is part of the larger networks supporting regional, national and international trade.

These considerations lead to a number of main concepts, which have hitherto been suggested as building blocks of city logistics systems, that we group into three main groups illustrated in Figure 2: (i) the system definition including the demand to be serviced, the type and number of facilities used, the layout of the network and the transport modes supporting the operations of the City Logistics network, (ii) the planning methods and procedures used to design, evaluate, manage and control the City Logistics system and its activities, and (iii) the administrative and business models adopted.

Using various combinations of these components shown in Figure 2 yield systems that are similar in essence but differ with respect to the actual configuration and the requirements in terms of analysis and planning tools. The three components are discussed 


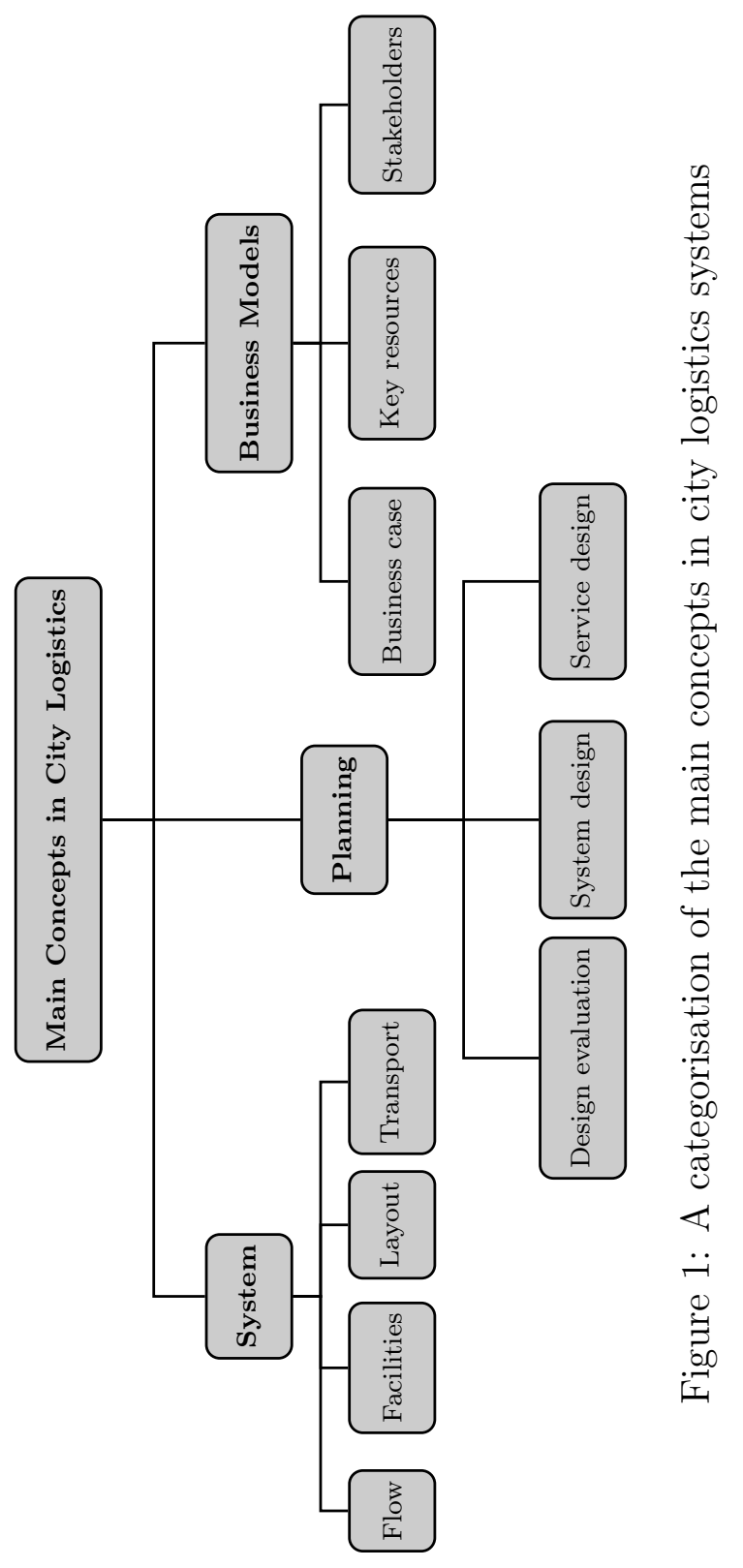


in greater detail in the three sections below.

\section{City Logistics Systems}

The system component of City Logistics is characterized by (i) the demand that is serviced determining the type of traffic that flows within the City Logistics network, (ii) the type and number of facilities used that, together with the representation of the customers of the system, make up the nodes of the network, (iii) the layout of the network defining how the facilities are arrayed within the city zone considered and how transportation services and routes proceed, (iv) the types of transport modes supporting the operations of the City Logistics network. We describe these individual subsystems in greater detail in the following sections.

\subsection{Flow}

This corresponds to the scope of City Logistics, the demand for transport the system aims to satisfy. It also defines the "users" of the City Logistics system and the nodes of the corresponding network, indicating where demands originate from, the shippers, and is destined to, the consignees.

Both shippers and consignees may be located outside or anywhere within the city zone serviced by City Logistics system. We therefore adopt the naming scheme of (Crainic et al., 2009a) defining external zones and customer zones (or, simply, customers) to represent shippers, consignees, and any other stakeholder or facility located outside and inside of the City Logistic area, respectively.

City logistics has primarily concerned itself with inbound flows describing freight being delivered to customers within urban zones from zones external to a given city. This particular type of demand and traffic flow has been named external zone-to-customer (e2c) by Crainic et al. (2012a), who also consider two other types of traffic, namely customer-to-customer (c2c), addressing demand among shippers and consignees located within the City Logistics area, and the outbound traffic named customer-to-external zone (c2e). The authors also present an elaborate discussion of a number of policies to serve a combination of flows, such as e2c+c2e using a shared fleet. Algorithms for planning such integrated services were proposed recently proposed by Nguyen et al. (2015b) and Bettinelli et al. (2015) for the e2c+c2e case, and by Nguyen et al. (2015a) for the integrated $e 2 c+c 2 e+c 2 c$ case. 


\section{$3.2 \quad$ Facilities}

Facilities are intermediate locations for the freight flows from shippers to consignees. They play a particularly important role in City Logistics as hubs for the consolidation of flows, the coordination of transport, transshipment, and storage activities, and the synchronization of vehicle movements. Indeed, as indicated in most of the City Logistics literature, significant gains can be achieved through a streamlining of transportation activities resulting in less freight vehicles traveling within the city. The consolidation of loads of different shippers and carriers within the same vehicles associated to some form of coordination of operations within the city are among the most important means to achieve this rationalization.

Two main types of facilities are generally considered within city logistics networks, city distribution centres and satellites.

City distribution centres (CDCs), alternatively called urban-freight consolidation centres (UCCs), are often seen as being similar to intermodal logistics platforms or freight villages (Benjelloun and Crainic, 2009) albeit "tailored" for urban settings. The primary purpose of CDCs is to receive inbound freight for operations such as storage, sorting and consolidation, so as to achieve a coordinated and efficient delivery within cities. When c2e traffic is addressed by the City Logistics system, CDCs also receive the freight collected within the city, and prepare it for the long haul part of its journey. CDCs are often located in the boundaries of the urban zone.

Despite a number of not-so-successful implementations emphasizing the need to address City Logistics at a system, network level, including the Business model component, CDCs are instrumental in most proposals and projects, e.g., Browne et al. (2006); van Duin (1997); Janssen and Oldenburger (1991); Kohler (1997, 2001); Ruske (1994); Taniguchi et al. (2001a); Thompson and Taniguchi (2001); Van Rooijen and Quak (2014).

Satellites are similar to CDCs but differ with respect to location and functionality (Crainic et al., 2004; Gragnani et al., 2004; Benjelloun and Crainic, 2009, Crainic et al. 2009a). As for the former, they can be located within the urban zone, even in dense areas. Existing facilities, such as parking lots, bus exchanges or rail stations/stops can be used as satellites. As for the latter, satellites are generally intended as "rendez-vous" points, where freight is transferred from one vehicle to another, ideally in a trans-dock, synchronized fashion.

Satellites with limited warehousing facilities start to be studied and implemented, however, giving rise to the third category in Figure 2 Such facilities are particularly found in private-driven initiatives (e.g., Huart, 2011) and Interconnected City Logistics structures (Crainic and Montreuil, 2015). 


\subsection{Layout}

The term tier or echelon is often used in the context of city logistics to describe a set of entities that, for planning purposes, serve similar functions. Entities comprising a tier need not necessarily be within close geographical proximity. The two basic configurations seen in city logistics networks are of single or multi-tier type.

Single-tier city logistics systems operate one level of consolidation-distribution activities only, with distribution routes starting at a CDC and delivering the loads directly to the citizens. City logistics projects initially undertaken in Europe and Japan were based on the single-tiered concept, mostly involving a single CDC and a limited number of shippers and carriers. Different business models and strategies were tested (see the references above to CDC literature and Taniguchi et al., 2000; Visser et al., 1999)). Simulation (Barceló et al., 2007) and optimization for location of facilities (e.g., Taniguchi et al., 1999) and real-time routing of vehicles (e.g., Taniguchi et al., 2001b; Thompson, 2004) methodologies have been proposed for single-tiered systems. Such systems are well suited for small cities.

Multi-tier systems. More advanced systems are emerging that handle the complexities of large cities. The majority of such systems have a two-tiered structure, involving several types of facilities and transport modes and fleets. Typically, loads are first consolidated at a CDC into large vehicles, which bring them to a satellite "close" to the city center. This makes up the first tier of the system. Loads are then transferred to smaller vehicles, appropriate for city center activities, which then deliver to customers, thus making up the second tier of the system.

One notices a significant trend in investigating and deploying two-tier systems by private firms, express courier and last-mile delivery companies, in particularly, as well as by associations of carriers and logistics service providers (e.g., De Souza et al., 2014; Huart, 2011). Particularly noticeable is the constant increase in home delivery activities (e.g., Ducret and Delatre, 2013; Visser et al., 2014) due to the significant increase in the volume of personal e-shopping, and the new two-tier services addressing the issue. Although still in the first stages of development, an associated trend concerns the utilization of private or public mass-transport modes: rail for freight or people bringing loads to a "central" station, light passenger rail, buses, and barges when canals are part of the city (e.g., Diziain et al., 2014, van Duin, 2013; Masson et al., 2015).

Such trends multiply the types of facilities and transportation modes used, leading to true multi-tier systems that adapt operations and resources to each distinctive city area. The Interconnected City Logistics concept proposed by Crainic and Montreuil (2015). illustrates these developments. The scope of City Logistics is thus continuously broadening, encompassing the entire city. 


\subsection{Transport}

Most City Logistics projects and deployments are uni-modal, relying exclusively on motor vehicles to move freight. The focus is then on the type of truck most appropriate to the particular application or system layout, a constant preoccupation being the utilization of environment-friendly vehicles (e.g., with electric or gaz motorization).

A growing number of projects open up to multi-modal systems, the utilization of private or public mass-transportation modes being increasingly studied. Light rail, already used in at least one industrial context, has been mostly examined as the main mode in the first-tier of a two-tier system. The second tier was provided by a fleet of electrical vehicles that net specially designed trams at predefined sites and time moments ("virtual" satellites) for transshipment of a full load (by mechanical means embedded into tram). Sidelines could also be planned, as in a current study in a large European capital city, providing more flexibility to the satellite operations.

Studies have also examined, and sometimes implemented, the possible utilization of regular rail to bring freight into the very center of the city, of barges for cities with extensive canal networks, and even buses. At the other end of the spectrum with respect to vehicle capacity, several projects and actual deployed systems focus on various bicycle designs for delivery and pick up activities. Bicycles are already used in express letter and small parcel delivery within the city center and such utilization on a broader scale is actively researched. In all cases, the resulting multi-tier, multi-mode City Logistics systems require advanced methodology for the design and planning of the system and its operations. Efforts are under way, see Section 4, but most is still to come.

City Logistics are, in fact, multi-modal systems aiming to become intermodal. Indeed, similarly to long-haul freight transportation, the use of standardized containers could significantly increase system performance. Such boxes need to be appropriate for a large gamut of goods and to offer the capability of easily combining them (staking vertically and horizontally) into larger units for efficient handling and transfer. A major effort is currently underway to design such standard, modular, smart and reusable boxed, from the size of small cases up to that of cargo containers (Montreuil et al., 2015). Handling systems, vehicles and carriers are also designed or retrofit to seamlessly and efficiently deal with such boxes.

\section{$4 \quad$ Planning}

City Logistics translates into complex consolidation-based transportation and logistics systems characterized by multiple and diverse stakeholders, layers of facilities, trans- 
portation modes and fleets, and so on. Similar to any complex transportation system, City Logistics transportation systems require planning at the strategic, tactical, and operational levels of decision making (Benjelloun and Crainic, 2008).

Because of its particular nature that has it operate within urban areas aiming for a number of social, sustainable, and "public utility", objectives complementing the more traditional economic ones, City Logistics also requires methods to help decide on deployment, as well as evaluate designs, policies, rules, behaviour and performance. Formally, the latter issues belong to the strategic level of planning, but we prefer to treat them separately in Section 4.1, as they require different methodologies, and concern often different stakeholders, than those for the planning of City Logistics system at the strategic and tactical levels, which are examined in Sections 4.2 and 4.3 , respectively.

Decisions made at an operational level of planning often pertain to fleet and resource management, such as vehicle routing, scheduling, repositioning, assignment. Such issues

are intensively studied in the general literature (e.g., Toth and Vigo, 2014) for both people and freight transportation. These issues have been less addressed within the City Logistics context, except for a limited number of vehicle routing contributions within, e.g., simulation (Barceló et al., 2007), real-time information and decision making (Taniguchi et al., 2001b; Thompson, 2004), and planning (Perboli et al., 2011; Hemmelmayr et al., 2012; Crainic et al., 2008, 2011b; Nguyen et al., 2013, 2015b a; Bettinelli et al., 2015). A review of this topic is beyon the scope of this chapter. We discuss in Section 6, however, the unique opportunities that City Logistics offers for the integration at an operational level of planning of the currently separate lines of research focused on people and freight, respectively.

\subsection{Design evaluation}

This set of activities refers to the evaluation of the probable behaviour and performance of proposed systems and operating policies under a broad range of scenarios. In particular, the choice of a particular City Logistics structure, e.g., the choice of single or multi-tiered network, the business model employed, partnerships, and involvement of public transportation modes or infrastructures, should be based on cost-benefit analyses performed using strategic and tactical planning models. The design evaluation also addresses a continuous analysis of deployed systems and the planning of their evolution both as stand-alone systems and in relation to the general transportation system of the city and the larger region that encompasses it.

The methodology of choice for evaluating transportation systems is simulation. Several methodological approaches are available, each responding to a different need. All need to represent, however, the main components of the transportation system, their individual behaviour, and their interactions generating the behaviour and performance 
of the system. Cast in a freight vocabulary, these components are:

1. Demand modelling capturing what desires or needs to be moved by the transportation system and how these decisions are made. Demand modelling includes the specification of the user types or product definitions, and the identification of producers, shippers, consignees and intermediaries that generate the origin-todestination (OD) volumes to be moved, together with their respective criteria when deciding how the volumes should be moved. The results of the demand modelling generally are the production, consumption, and OD volumes to be moved, as well as mode or itinerary choices for transportation.

2. Supply modelling yields a representation of the transportation systems in terms of points of origin and destination of the traffic (in many classic evaluation methods, these are known as centroids, capturing the entire inbound and outbound demand in the surrounding zone), the physical infrastructure linking these points, as well as all the so-called intermediary points required for a correct representation of the infrastructure network (e.g., street intersections), the carriers with their modes, services, and lines, the vehicles and, eventually, convoys, the terminals and intermodal facilities. The characteristics of these means of transportation, e.g., capacities and congestion measures on the infrastructure and in terminals, together with a representation of the economic, service, and performance measures and criteria of the respective stakeholders completes the supply modelling. This representation may take the form of a multimodal, multicommodity network. It may also represent at a more aggregated level the entities, public governments, transit authorities, freight carriers, logistic service providers, and so on, that offer or facilitate the movement of freight through the city,

3. Simulation engine. This procedure simulates the behaviour and performance of the transportation system, that is, the interactions between the demand and supply stakeholders, including public authorities though their rules and policies regulating activities and traffic, and yields the measures (flows, travel times, congestion levels, market shares, etc.) that form the basis for the strategic analyses and planning activities.

How one defines and interlinks these components yields various methodological approaches, embedded into more or less complex evaluation frameworks to account for the multitude of stakeholders with potentially different (divergent, in many cases) objectives (Ahrens, 2009; Balm et al., 2014; Taniguchi and van der Heijden, 2000; Taniguchi et al., 2001a: Taniguchi and Thompson, 2002, e.g.,). Thus, a number of methods and tools for the analysis, fusion, validation, and updating of data, as well as capabilities for the analysis of, e.g., financial and business model, cost-benefit trade offs, environmental impact, and energy consumption policies, usually complement the methodology. 
Agent-based simulation models have been proposed to evaluate possible single-tier City Logistics configurations with different stakeholder involvement (e.g., Tamagawa et al., 2010; van Duin et al. 2012; Wangapisit et al., 2014) The agent methodology provides the framework to define classes of stakeholders and a large number of individuals within each class, potentially each with an individual procedure defining its activities (e.g., vehicle routing algorithms for carrier agents) and behaviour in interacting with the other agents, as well as communication and learning mechanisms. Such methodology appears appropriate to evaluate proposals at a rather aggregate level, where the competition or collaboration among stakeholders may be represented (through, e.g., economic/game theory models). It appears less amenable to the representation of the flows on the supply network and the interaction among freight people in individual vehicles and public transit.

Applications to large-scale, multi-tier City Logistics systems are still to come. These will have to address the challenge of integrating both the advanced network and service design methods (Sections 4.2 and 4.3) required to model the activity of carrier and terminal stakeholders, and comprehensive demand models (e.g., Boerkamps and van Binsbergen, 1999; Patier, 2002; Meimbresse, B. and Sonntag, H., 2001; Ambrosini and Routhier, 2004; Friedrich et al., 2003; Gentile and Vigo, 2007; Holguín-Veras and Thorson, 2003; Holguín-Veras and Patil, 2008; Nuzzolo and Comi, 2014a b)

Optimization-based methods appear better suited to incorporate a detailed network representation and simulate the movements of the vehicles and loads on this network together with the interactions with the flows of vehicles transporting people. Equilibriumbased principles have led to the methods and software products is general used around the world today (see, e.g., Cascetta, 2001, Crainic and Florian, 2008; Florian, 2008; Florian and Hearn, 1995). So-called static methods, use a detailed multimodal network representation and O-D demand estimations (and forecasts; these generally are modechoice specific) for several classes of users. The simulation engine is then an assignment procedure implementing a non-linear traffic assignment model minimizing a generalized cost function that generally takes congestion into account. The software instruments generally also include a methodology for the assignment of user demand to the lines making up the public transport system. The integration of the two methods is still a challenge, however, as is a better representation of freight demand and flows. This class of methods has a long and distinguished track record and, despite the emergence of dynamic traffic simulators mentioned in the following, it will continue to be used for a good time to come for tactical and strategic evaluation issues. An important but very challenging research perspective is therefore the exploration of how to integrate City Logistics systems in to such methods and instruments.

Dynamic traffic simulation aims to "follow" vehicles as they make their way through the network and interact with the other vehicles of the modes considered. Vehicles may be followed individually or "grouped" according to the desired level of detail (the more 
detailed the level of vehicle following, the higher the computation time required and, thus, the smaller the dimension of the network considered). Dynamic traffic simulation appears appropriate for the evaluation of City Logistics as it can capture how the corresponding vehicles circulate through the city, interacting with the individual and collective means of transportation, as well as with the freight vehicles operating outside the City Logistic system (if any), and how the proposed infrastructure and services would be used. Such simulators require, however, a route-generation mechanism that determines the trajectory of each (group of) vehicle. For City Logistics, these are the same models and methods that are required to plan and control operations for an actual system, that is service design (Section 4.3) and routing models. We are aware of only one fully-developed contribution Barceló et al. (2007), where a traffic micro-simulator is coupled to a City Logistics routing model. This methodology has been used to evaluate City Logistics projects for small European cities, but appears difficult to scale for larger urban areas. Mezo-traffic simulators Mahut et al. (2004); Florian et al. (2008); Mahmassani (2001); Mahmassani and Abdelghany (2003), addressing larger urban zones, coupled to tactical planning models offer promising perspectives, but no contribution to this area has been made yet.

\subsection{City Logistics network design}

The design of City Logistics networks is generally addressed through mixed-integer, combinatorial discreet-choice location models and, more rarely, network design formulations. The literature on network design and facility location is huge and a review is well beyond the scope of this chapter. The interested reader can consult a number of books (e.g., Daskin, M.S., 1995; Drezner, 1995; Drezner and Hamacher, 2002, Labbé, M. et al., 1995; Mirchandani, P.S. and Francis, R.L., 1990), and survey papers (e.g., Ambrosino and Scutellà, 2005; Balakrishnan et al., 1997; Campbell, J.F., 1994b; Crainic, 2000, 2003; Crainic and Kim, 2007; Drexl and Schneider, 2014, 2015; Grötschel et al., 1995; Klose, A. and Drexl, A., 2005; Laporte, 1988; Magnanti and Wong, 1984; Mina et al., 1998; ReVelle, C.S. and Eiselt H.A., 2005; Prodhon and Prins, 2014). The literature focusing on City Logistics network-design issues is more sparse, but one observes an increase in the pace of publication of new contributions.

City Logistics networks are generally superimposed on the transportation and logistics infrastructure of the city. Very rarely the design of such systems involve the opening of new streets or the construction of new rail or bus infrastructure. The situation is of course different when underground transportation systems are contemplated van Duin (1998); Ooishi and Taniguchi (1999) in which case, network design methodologies would apply. The cost of such systems makes them unattractive in most case, however, and the authors are not aware of any significant contribution addressing their design.

Consequently, the design of City Logistics networks focuses in most cases on decisions 
on the number, characteristics, layout, and location of facilities such as CDCs, satellites, and so on. In all generality, strategic design models should also select the City Logistics network, e.g., the access/egress corridors and the street networks open to each vehicle type and the determination of the vehicle fleets composition and size, but very few contributions address this general case.

It might be interesting to recall that location and, more generally, network design problems integrate two levels of decisions. The selection level focuses on the choice of nodes or arcs to add to the network, and the related cost, through integer (binary)valued decision variables. The utilization level (the terms assignment, distribution, and transportation are also used) evaluates the future use of a design to service the associated demand. This evaluation is performed on a more or less detailed network with continuous or integer flows. The "general wisdom" of the field tends towards more detailed network representations conducting, for example, to a preference for location-routing formulations rather than location-allocation ones, even though these are more difficult to address. This observation also applies to contributions to City Logistics. Yet, there is a real need for more research into the actual value of the level of utilization detail, particularly within the context of very large City Logistics applications. The development of approximation techniques appears an interesting research avenue in this context, particularly as it might provide a simpler way to deal with the uncertainty of using a transportation network.

\section{Single and multi-tier location.}

Taniguchi et al. (1999) presented what might very well be the first model for the location and dimensioning of facilities for a single-tier City Logistics distribution system. Proposed before the "City Logistics" term was broadly adopted, the facilities were identified as "public logistics terminals" or "multi-company distribution centers". They were seen as a mean toward cooperative freight systems supporting more efficient logistics systems and, thus, as a measure to help address the serious challenges Japan was facing in terms of traffic congestion, environment, energy and labor costs. The system contemplated by the authors targeted the freight movements within a large area, the transportation network being separated into a long-haul part for large vehicles (the expressway network, mainly) and a pickup and delivery part for a different fleet of small trucks. Origin to destination demand was identified for each type of network, the terminals being indented to reduce the total generalized cost of the system that included the costs of transportation, terminal set up and utilization, pollution, and so on. The facility-location decisions were assigned to some authority, while trucking companies, or individual drivers, selected the terminals to visit and the routes to perform. The proposed formulation included two models, a high-level one to select and dimension facilities, and a non-linear traffic-equilibrium-type model reflecting congestion and the choice behaviour of the truck carriers at the lower level. Experimentation was carried on on a small-scale application using a very aggregated representation of the road network in the Kyoto-Osaka region of Japan. 
Even though the approach of Taniguchi et al. (1999) described above was not followed by subsequent contributions, it opens very interesting research avenues including the adaptation of recent results in bi-level programming, the modelling of various business and operational City Logistics organizations, and solution methods able to address realistic-sized problem instances.

Crainic et al. (2004) formally introduced the two-tier City Logistics structure, together with a location-allocation model targeting the selection of sites for satellites (the intermediate facilities). The model was presented as a means toward a proof-of-concept for the potential benefits of two-tiered City Logistics, and actual data from the city of Rome was used to estimate the demand for freight distribution, the division of the city in customer zones, the identification of possible sites for the satellites, and the cost of moving within the city from the city entry gates to satellite sites and to customer zones, and from satellite sites to customer zones. This simplified problem definition assumed one product only (boxed "loads").

Baldi et al. (2012) addressed the same problem but considered explicitly a stochastic cost, with unknown probability distribution, from external zones to customers via a satellite (path-flow formulation). The authors approximated the stochastic formulation with an equivalent deterministic model belonging to a rather wide class of Entropy maximizing models, and showed empirically the correctness of the approximation. Small-scale instances were used for the experiments performed using off-the-shelf software.

\section{Location-routing.}

Location-routing formulations (Drexl and Schneider, 2014, 2015; Prodhon and Prins, 2014). aim to capture the intricacies and cost of using the system to deliver and pick up goods using the facilities one desires to locate. The utilization part is therefore modeled on a network representing either the direct movements that are allowed in the system, or the actual infrastructure (e.g., street) network used to perform the routes. The former case corresponds to the representation generally used in the vehicle routing field, the actual infrastructure network being then used to compute the distance (cost) matrix.

Crainic et al. (2008, 2010, 2011b, 2012b) did not propose proper location-routing models, but used meta-heuristics for routing in two-tier systems to perform various studies of the impact on the system efficiency of satellite-location decisions. The system studied had one external CDC facility, a rather small number of satellites, and between 32 and 150 customer zones. The authors developed a clustering-based constructive heuristics combined to a number of local-search methods aimed at solution improvement, and showed that this method performs well on the instances studied, outperforming a meta-heuristic based on solving a multi-depot VRP, and even an exact solution method (Perboli et al. 2011) for the larger instances. This method was used to perform several studies, varying the number of satellites and their location with respect to different city geographical 
layouts and number and distribution of customers. The studies showed that, compared to a single-tier system with a central terminal facility, the tow-tier system may reduce significantly the total distribution costs. The authors also emphasized the need for more research on two-echelon vehicle routing problems. Despite some very interesting recent developments, (e.g., Contardo et al., 2012; Hemmelmayr et al., 2012, the latter being the current best meta-heuristic for $2 \mathrm{E}-\mathrm{VRP}$ and also a very good method for location-routing of satellites in a two-tier City Logistics system) this conclusion is still true regarding both the problem settings addressed (e.g., time and synchronization issues are largely absent) and their dimensions.

Guyon et al. (2012) proposed what may be the first location-routing model for City Logistics. The authors addressed a single-tier system where vehicles were delivering parcels from logistics platforms to demand zones inside the city. The problem is defined on a direct-movement network, where a factor accounting for congestion effects within each zone is added to the actual travel distance. Vehicles were capacitated and their operations where limited by a total route length and duration (including service time at customers). Moreover, each demand zone had to be serviced by a single vehicle. The facility capacities, in number of bay doors for vehicles, had to be determined together with the selection of facilities and the usual vehicle routing decisions. The generalized objective function encompassed terms reflecting the economic cost and the environmental impact of the system, as well as the social acceptability of the facilities by the population. The integer programming formulation was solved using a commercial software embedded into a user-friendly platform. The benefits of the proposed system and the performance of the methodology were shown through an application to the city of Marseilles.

Gianessi et al. (2015) (see also Gianessi, 2014) consider location decisions on a single tier only, but integrate design decisions related to part of the transportation network. The authors work on a City Logistics organization, introduced in an associated project, based on a ring of CDCs that collect the massive e2c (inbound) and c2e (outbound) flows of freight with destination and origin within the city, respectively. E2c (c2e) vehicles get into (out of) the urban region through specific points called gates (these are not facilities in the variant studied). To avoid excessive travel, vehicles are directed to one of a specific subset of CDCs associated to (close by) its gate. Once at a CDC, freight is either distributed directly to customers, or is first moved to another CDC, closer to the zone of the city where customers are located, and distributed out of that facility. This structure is intended to avoid excessive travel within the city, and it thus uses a ring of transportation infrastructure or services circling the controlled zone. The authors also consider c2e demands with given outbound gates. This yields a pickup and delivery problem between the CDCs and the customers. The ring location-routing problem addressed by the authors encompasses decisions on the selection of the CDC locations, the selection of the CDC-to-CDC links in the ring structure circling the city, as well as the freight routing from its respective gate, to a first and, possibly, a second CDC, and then to the final customer (reverse routing for c2e demands). The second set of decisions corresponds to 
the construction of a Hamiltonian ring linking the selected CDCs, while the third implies the assignment of demands to selected CDCs, the determination of multicommodity flows between gate and CDCs and among CDCs, plus, obviously, the construction of pickup and delivery routes. A number of additional characteristics are considered as well, e.g., vehicle capacity and route length limits, open routes (i.e., not returning to the starting facility), extra vehicles available for hire, and fleet repositioning at the "end of the day". Time aspects are not considered.

The authors propose a mixed-integer formulation combining binary variables for the location and design decisions, continuous arc-flow variables on the superior network, between gates and CDCs and on the Hamiltonian ring, and binary route-selection variables for the vehicle routing problem between CDCs and customers. The authors propose a number of valid inequalities to strengthen the formulation and a matheuristic solution method that decomposes the problem into several main blocks: route generation, selection of facilities and demand assignment, ring construction, and ring flow determination. The first is addressed through a nearest-neighbour heuristic, while the others are treated by solving exactly the reduced mixed-integer formulation. As expected, a commercial solver can solve tiny instances only. A hybrid heuristic, solving exactly the problem on the reduced set of routes produced by the first block above, gave good results as the size increased, but the matheuristic had to be called on for larger instances (which were still not very large, however).

Sterle (2009); Crainic et al. (2011c); Boccia et al. (2011, 2010) are probably the first to study the integrated problem of locating facilities on two echelons of two-tier City Logistics systems, where the utilization of the resulting network is modelled through routing problems at each tier. It the two echelon location-routing problem (2E-LRP) setting considered, a set of capacitated CDC facilities has to be located on the first tier, while a set of capacitated satellites has to be located on the second one. Particular fleets provide service on each tier, urban vehicles moving freight from CDCs to satellites, while city freighters deliver it from these to customers. On each tier, vehicles perform closed routes, ending at the same CDC or satellite it started from. The authors considered e2c (inbound) traffic only, a single product, and no-split-delivery policy for distribution. Time and synchronization issues are not considered.

Three sets of decisions make up this core 2E-LRP, selecting facilities on each tier, assigning customers to selected satellites and satellites to selected CDCs, and routing vehicles on each tier. The authors proposed a classification of the different 2E-LRP, as well as several mixed-integer formulations: a three-index model, inspired by the work of Ambrosino and Scutellà (2005), which follows a classic modelling approach in the vehicle routing literature and includes a detailed arc-based representation of the routing decisions; a two-index formulation extending the model of Prins et al. (2006); a twoindex model inspired by the multi-depot vehicle routing problem (MDVRP) of Dondo and Cerdá (2007); and a path-based single-index formulation. 
The authors focused on the first and third formulations (Crainic et al., 2011c; Boccia et al., 2011). The first formulation is very flexible. It may be adapted to address 2E-LRPs with both symmetric and asymmetric cost matrices, and it may be extended to take into account features such as multi-commodity (origin-to-destination) demands and flows, time windows for customers and facilities, maximum route length constraints, heterogeneous fleets, and so on. On the other hand, it involves a very large number of variables and constraints, which makes it harder to solve. The MDVRP two-index formulation is less flexible (e.g., it is suitable for symmetric instances), and requires significantly less decision variables at the cost of more constraints. The authors introduced a set of problem instances of rather small dimensions and performed an experimental comparison of the two formulations using a commercial MIP software. The three-index one appears to perform better as the problem size increases (in number of potential locations), mainly due to the fact that the linear relaxation of the three-index formulation provides higher lower-bound values than the two-index formulation. Yet, the size of the instances that could be addressed is limited and the lower bounds are not sufficiently tight for efficient enumeration algorithms. Boccia et al. (2010) thus proposed a tabu search method for the same 2E-LRP setting. The method is based on decomposing the problem by tier, yielding a LRP on each that is then further decomposed into a capacitated facility location problem and a MDVRP. A greedy procedure is used to determine an initial solution. The tabu search meta-heuristic works on the two LRP subproblems through a feedback loop that returns to the CDC tier when a new solution for the satellite tier either improves the best solution found so far, or violates the capacity of a selected CDC. Classic routing neighbourhoods are used, e.g., 2- and 3-opt improvements of the solution of a saving heuristic, intra and inter-route customer shift and swap, facility location swap and facility. Compared to the results of the exact-solution experiments, the tabu search found the optimal solutions of all the small problems and improved the ones the exact method could not solve to optimality.

A significant methodological advance for the 2E-LRP was contributed by Contardo et al. (2012) who introduced a Branch-and-Cut (B\&C) algorithm and an Adaptive Large Neighbourhood Search (ALNS) meta-heuristic. These two methods are currently the best exact and meta-heuristic methods, respectively, for the 2E-LRP. The authors presented a new two-index arc-based formulation where, besides the binary variables representing the selection of facility locations and arcs used to move at each tier, continuous variables stand for the amount of flow shipped to and from each satellite. These satellite-flow variables facilitate the decomposition of the $2 \mathrm{E}-\mathrm{LRP}$ into two capacitated LRPs, one for each tier, representing the satellite demands in the CDC tier, and the satellite capacity in the lower tier, respectively. Both solution methods presented in the paper take advantage of the decomposition.

The authors showed that this formulation yields tight lower bounds appropriate for efficient enumeration algorithms and that it inherits most valid cuts valid for the capacitated LRP (Belenguer et al., 2010; Contardo et al., 2013). The proposed B\&C algorithm 
makes use of these cuts, together with the corresponding separation procedures, and introduces some new ones particular to the problem setting. The linear relaxation of the formulation provides the lower bound at each node, and the authors show that it is tight, much tighter than that offered by the formulations already in the literature. The proposed ALNS meta-heuristic is based on the same 2E-LRP decomposition idea, and iterates on the two LRPs. The first, CDC-echelon problem is addressed each time the new solution obtained in the lower tier implies a change in the satellite configuration. The structure of the algorithm follows that of the ALNS proposed by Hemmelmayr et al. (2012) for the two-echelon vehicle routing problem, which not only is the current best meta-heuristic for the problem, but is also one of the best performing meta-heuristic for the single-echelon LRP. Eight destroy and four repair operators were developed based on the ones in Hemmelmayr et al. (2012), and were used at both levels. Three destroy operators were dedicated to explicitly open or close a satellite, while the other five remove sets of customers only indirectly changing the satellite configuration. The repair operators have the same structure, select an open satellite, a route and an insertion position for every customer one needs to insert, but differ in the insertion criterion. A local search procedure is used to improve the lower echelon routes of promising solutions, i.e., those that improve or are close to the current best solution. An extensive experimental campaign showed that the $\mathrm{B} \& \mathrm{C}$ was able to solve to optimality problems with up to 50 customers and that it offered tight lower bounds on larger problems. On the other hand, the ALNS was able to address much larger instances, outperforming previous heuristics for the $2 \mathrm{E}-\mathrm{VRP}$ instances in the literature and identifying feasible solutions within some $3 \%$ of the lower bounds identified by the B\&C for the $2 \mathrm{E}-\mathrm{LRP}$.

The design of City Logistics networks presents considerable methodological challenges, as illustrated by the contributions reviewed above. Yet, despite the work already accomplished, many more are still to be addressed.

Modelling the various City Logistics configurations for comprehensive representation of the system configuration and operations, the stakeholder behaviour, and the design and planning issues involved, as well as for the efficient solution of instances of realistic size is a major challenge. It should be noted that most City Logistics systems have received very little formal attention important aspects being regularly neglected. Thus, for example, little attention has been bestowed on the multiple demand and traffic types that exist in urban settings (Crainic et al., 2012a) and the associated complex routing problems, particularly when operating hours and synchronization of activities are taken into account (Bettinelli et al., 2015; Nguyen et al., 2015ba). Many other settings, e.g., the Interconnected City Logistics of Section 6.3 and multi-stakeholders systems, have not yet been addressed at all. Models and methods have been proposed for very few alternatives, and most such contributions addressed very simplified settings. These developments were necessary and more are needed, as basic versions offer the fundamental expertise and building blocks to address more comprehensive systems. 
Methodological, algorithmic, work is therefore required for the complex design models City Logistics generates. Challenging development issues exist for exact solution methods - of the Branch\&Cut\&Price type -, as well as advanced meta-heuristics and matheuristics combining meta-heuristic search and the solution of particular optimization problems. To address realistic problem instances, parallel computing will have to be called upon. The combination of parallel computing and meta-heuristic search, as illustrated by the Integrative Cooperative Search (Crainic et al., 2009b; Lahrichi et al., 2015).

Last but not least, the uncertainty inherent to city development and the activities of the transportation network have yet to be considered and integrated into the design models. This modelling challenge is compounded by the methodological one of addressing realistically-dimensioned formulations the representing the stochasticity of demand, activities, or both.

\subsection{City Logistics service design}

City Logistics systems belong to the important class of consolidation-based transportation systems that include rail and less-than-truckload carriers, high-sea navigation lines, intermodal systems, express courier and postal services, and so on. Tactical planning for such systems aims to build a transportation (or load) plan to provide for efficient operations and resource utilization, while satisfying the demand for transportation within the quality criteria (e.g., delivery time) publicized or agreed upon with the respective customers (Crainic, 2000, 2003; Crainic and Kim, 2007). The scope of the process is to select the services to operate (routes, types of vehicles, speed and priority, and so on) and their schedules, determine the policies and rules guiding the classification and consolidation of freight and vehicles at terminals, chose the itineraries to move the freight between each particular origin-destination pair (for each product and customer, eventually) and, increasingly, determine broad resource-management policies (in particular those related to the management of the fleet, e.g., empty-vehicle repositioning, power allocation and circulation, etc. Pedersen et al., 2009; Andersen et al., 2009a b; Crainic et al., 2014).

Tactical planning models for City Logistics concern the departure times, routes, and loads of vehicles, the routing of demand and, when appropriate, the utilization of the satellites and the distribution of work among them. Such models assist the deployment of resources, the planning of operations and the scheduling of personnel, and guide the real-time activities of the system. They are also important components of models and procedures to evaluate City Logistics systems, from initial proposals to deployment scenarios and operation policies. Yet, very few contributions to tactical planning methodology for City Logistics may be found in the literature. This may possibly be explained by the focus that most contributions to the City Logistics literature adopted until very recently on routing vehicles out of the CDC facilities of single-tier systems. 
Crainic et al. (2009a) and Crainic et al. (2015) (see also Mancini et al., 2014) present an in-depth discussion of the issues and challenges of tactical planning for City Logistics operations, emphasizing two-tier systems. Crainic et al. (2009a) also represents the seminal work in this field.

The authors present a detailed description of two-tier City Logistics system organization, operations and planning issues. They then introduce a comprehensive generic methodological framework for tactical planning of operations considering several modes, vehicle types and products, proposing formulations and an algorithmic scheme (see Crainic et al., 2009c, for an application of the methodology to the single-tier case). Their model focuses on the day-before tactical planning problem, where a plan is built every day for the entire system given the particular demand for that day. The application of the methodology to broader planning issues was mentioned but not detailed.

The model takes the form of a time-dependent two-tier service network design pathbased formulation. Customers are grouped into customer zones with hard time windows, service times, and product-specific demands from particular CDCs. Physical locations for first and second tier facilities, CDCs (external zones) and satellites, respectively, as well as customer zones are duplicated for each period of the planning horizon contemplated, First and second tier services make up the links of the network, together with holding arcs at facilities and customer zones. On the first tier, one selects urban-vehicle services, which may belong to various transportation modes, identified by their route from a CDC to a number of satellites and either returning to a first-tier facility (not necessarily the same as the departure one) or exiting the system, the vehicle characteristics, their departure time and their schedule of arrival and departure at each satellite on their route. The second tier services correspond to city-freighter work assignments (called "segments" in the paper) defined as time-dependent multi-tour routes starting from the garage of the specific fleet considered at a particular time period and, then, visiting a series of satellites to load and deliver to a number of customers until the route length or other time restrictions force the route to end by returning to the garage. Travel times on all tiers are considered to be time-dependent to reflect "usual" traffic conditions and congestion.

The presence of interacting urban vehicles and city freighters at satellites is to be synchronized, the transshipment of loads from the former to the latter being assumed to be performed according to transdock rules (no intermediate storage) with very limited waiting space for vehicles. Customer itineraries, defined as paths through the service network, made up of a first tier service, a transshipment at a satellite and a city-freighter route, enforce this requirement and ensure the timely delivery of loads to customers.

Services on both tiers are represented as paths in the time-space network, and two sets of binary decision variables are defined to select services in each. A third set of binary decision variables are introduced to select customer itineraries. The integer path-based network design formulation then minimizes a generalized total cost function that includes 
operating and "nuisance" costs for each type of vehicle, the latter reflecting the impact of operations at particular time periods at specific locations within the city. The constraints enforce single-delivery to customers (i.e., single-itinerary selection; split-delivery models were introduced in the technical reports Crainic et al., 2005, 2007), vehicle and satellite capacity restrictions (the latter in numbers of vehicles on all tiers), and fleet size. The authors also present the extension of the formulation to address first-tour multi-tour services, as well as a simplified formulation for strategic-evaluation purposes (the secondtier routing component is replaced by an approximation of the cost to deliver to each customer out of each admissible satellite).

The authors presented an analysis of their formulation noticing that one may consider it either as a combination of scheduled service network design (first tier) and vehicle routing with time windows within a synchronized time-dependent framework, or as a two-level synchronized multi-attribute vehicle routing problem. They identified the latter as a new VRP variant and called it the two-echelon, synchronized, scheduled, multidepot, multiple-tour, heterogeneous vehicle routing problem with time windows problem (2SS-MDMT-VRPTW). They then proceeded to detail the first-tier scheduled service network design problem and the synchronized, scheduled, multi-depot, multiple-tour, heterogeneous vehicle routing problem with time windows (SS-MDMT-VRPTW), the new VRP variant making up the second tier (a full arc-based formulation is provided). They concluded by suggesting a decomposition approach based on iterating through the first and second tier formulations, but no actual implementation was described.

Huart (2011) presented a day-before planning model for the intra-muros operations of a group of carriers and warehousing-capacity providers sharing information and resources that become available at particular moments only. The problem setting thus focuses on the the second tier, assuming loads are already brought to some facility within the City Logistics area of the city. The final distribution is then to be performed using the vehicle and temporary storage capacity offered by the participating stakeholders. Short-term storage and transshipment capacity is available at specified time moments for given time windows. Moving capacity is provided by vehicles with predetermined work assignments that are fully or partially (with residual capacity) available for a certain time (waiting for the next planned assignment) between given origin and destination zones. The objective is to minimize revenue, unprofitable demands may be rejected, through a coordinated planning of activities and resource utilization. The model accounts for several types of commodities, vehicles, and facilities, as well as for the compatibility restrictions between commodities and vehicles and between vehicles and facilities. The formulation is based on a multi-layer time-space network, each vehicle, facility and demand making up a layer. Several sets of time-dependent binary decision variables define the assignment of loads to vehicles and facilities, the selection of arcs for the routing of vehicles and of facilities for transshipment operations, and for short-term warehousing of demand at facilities. A number of time and geography criteria provide the means to reduce the size of the resulting problem. The author also examines extensions of the formulation to address 
a number of issues, e.g., transportation modes on fixed infrastructure such as trams or subways and clustered demands that must be accepted or rejected together.

Planning, tactical planning in particular, assumes a certain level of look-ahead capability and the inclusion of an evaluation of future events and their consequences into today's decision processes. Tactical planning is based on a demand forecast for the planning horizon considered, and the choice of an appropriate methodological approach is directly related to the magnitude of the demand variability and the confidence one has in the demand forecasts. As discussed by Crainic et al. (2015), a series of problems and formulations may then be identified starting from particular answers to these questions, from total confidence in forecasts of low variability, to high variability of demand combined to a low or no confidence in the possibility to adequately forecast it. Deterministic models as reviewed above are adequate for the former alternative, while the second is characteristic of the no-tactical-plan, quasi real-time vehicle dispatch situation, observed in many fleet-management situations, requiring explicit representation of system and information dynamics and uncertainty (e.g., Powell, 2003; Powell et al., 2007; Powell, 2011). No contribution to City Logistics planning has yet been proposed for this setting but, as observed by Crainic et al. (2015), the case is somewhat different from the general fleetmanagement case. Indeed, given the advanced information systems normally linking the customers, carriers, and managers of City Logistics systems, it is reasonable to expect the system to be aware of most orders passed by customers as well as of the planned day of arrival and distribution time window. This case then corresponds to the day-before planning problem class described above, the Crainic et al. (2009a) formulation providing the deterministic basis to construct the stochastic model.

Between these extreme cases, one finds the many problem settings where one represents the future demand through some probability distribution and the impact of demand uncertainty on the tactical plan through two-stage stochastic programs, where the design decisions selecting the service network appear in the first stage, while routing is decided in the second (Lium et al., 2009; Crainic et al., 2011a; King and Wallace, 2012). Crainic et al. (2015) discuss this problem setting in the context of two-tier City Logistics and conclude that the tactical plan should select first-tier scheduled services, departure times and satellites visited, identify the satellite workloads at each moment during the day in terms of customers to service (together with an estimation of the corresponding number of city freighters) and numbers of vehicles of both tiers to accommodate. The plan is then to be instantiated for each day once the demand is known by determining the actual routing of the city freighters and, possibly, adding extra vehicles as needed and slightly modifying the service network.

The authors then proposed a two stage stochastic formulation for the tactical planning of two-tiered City Logistics systems. Based on the modelling framework of Crainic et al. (2009a), the formulation follows the ideas above, selecting first-tier services and partial itineraries in the first stage to minimize the expected generalized cost of the sys- 
tem over the planning horizon. This cost includes the approximated cost of using the satellites and delivering the demand, and the expected cost of the recourse actions to adapt the plan to the observed demand (the second stage). The authors proposed four recourse strategies. The first two work at the level of city-freighter routing only assuming the first-tier services and customer-to-satellite assignments fixed in the first strategy, and relaxing these assignments in the second. In the third and fourth strategies, the selected services where allow to slightly change their departure times to accommodate the observed demand (city-freighter routing is also part of these two strategies differentiated by fixing or not the customer-to-satellite assignments). The authors then experimentally compared the four strategies, as well as a "no-advance-planning" strategy, through a Monte-Carlo-like procedure. The strategies were compared in terms of system performance measures, transportation costs, number of demands serviced by direct delivery, vehicle capacity utilization, and utilization of the fleets and satellite facilities, as well as managerial challenges and trade-offs. The results underlined the benefits of consolidation (high utilization of vehicle capacity and low presence in the city) and managerial flexibility in modifying the allocation of resources.

The research needs and challenges are significant relative to the design of plans and service networks for City Logistics. A broader range of settings as well as of organization and business models must be addressed. Two cases to illustrate. First, most contributions present in the literature address inbound flows only. Crainic et al. (2012a) discussed issues related to the inclusion of $\mathrm{c} 2 \mathrm{e}$ and $\mathrm{c} 2 \mathrm{c}$ demand and traffic into planning models but, with the exception of a few recent contributions introducing such demands into the routing problem on the second tier of the system (Bettinelli et al., 2015, Nguyen et al., 2015b a), nothing has been proposed yet. Second, and equally important, one needs to extend the current modelling frameworks, or to invent new ones, to account for the various partnership strategies that are emerging. Such strategies specify the resources participating stakeholders (private carriers and facility owners/managers as well as, possibly, city governments and public transit authorities) bring to the system and how the costs, risks, potential benefits and resource utilization have to be performed.

There are significant challenges in terms of solution methods able to efficiently address such tactical planning models. Research has advanced on particular parts of tactical models, e.g., the first-tier scheduled service network design (Crainic and Sgalambro, 2014), the multi-tour synchronized vehicle routing problem with time windows (Nguyen et al. 2013, 2015b a) and the basic two-level VRP (Perboli et al., 2011), but an efficient methodology for the complete City Logistics service network design formulation has still be to proposed.

Interesting research avenues, that also present significant challenges, are related to the treatment of uncertainty. A few modelling efforts have been recently published (see above), but a more comprehensive effort is required, including the representation of travel and service time uncertainty. High-performance solution methods are also waiting to be 
developed. Given the difficulty usually associated to solving even modestly-sized stochastic network design problems, parallel multi-search matheuristics, efficiently combining meta-heuristic and exact search strategies (e.g., the Integrative Cooperative Search of Crainic et al., 2009b; Lahrichi et al., 2015), offer the most promising development directions.

\section{Business Models}

The Business Model Canvas is a strategic management template for developing new or documenting existing business models (Osterwalder and Pigneur, 2009). Specifically, as seen in Figure 2, it is a visual chart with key elements describing a firm's or product's value proposition, infrastructure, customers, and finances.

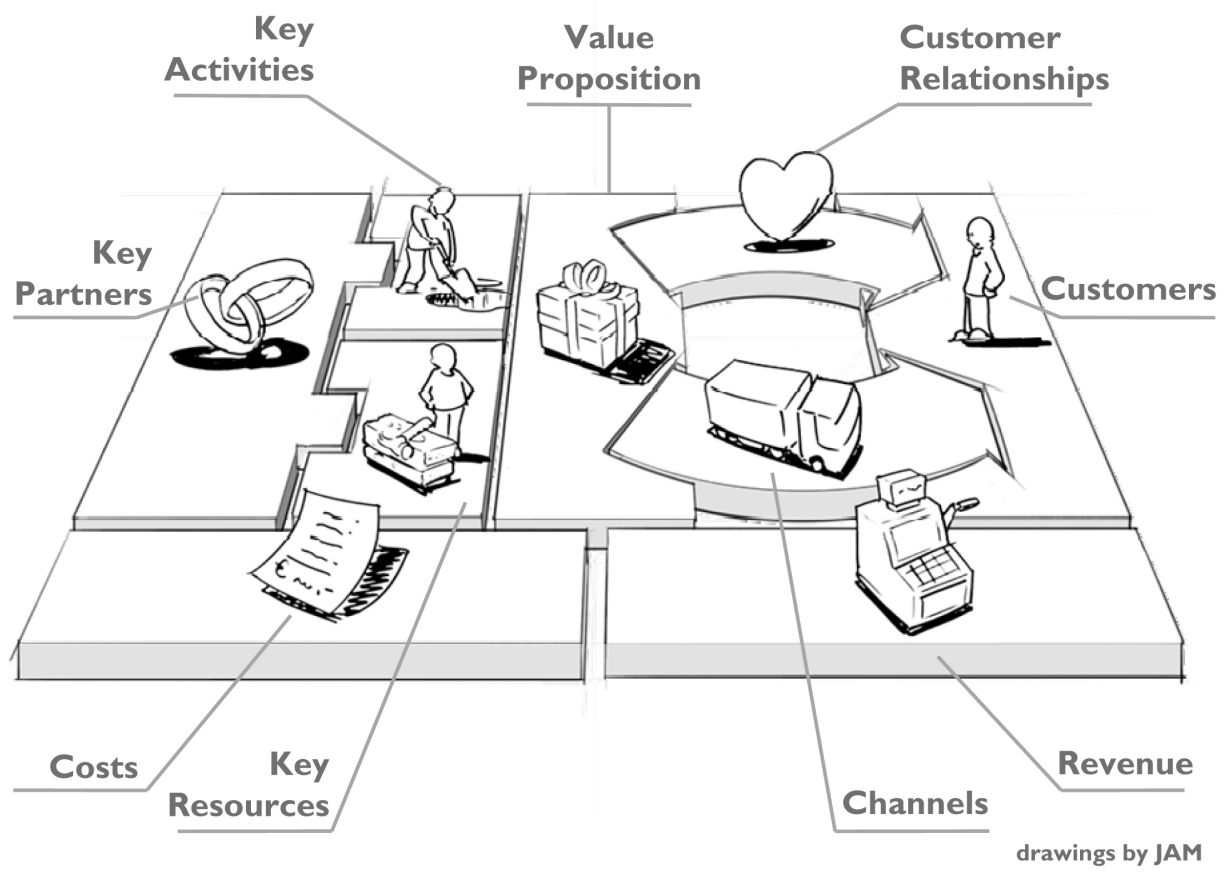

Figure 2: Business Model Canvas Illustration

The canvas is interesting to analyse new business concepts, as the set up of new city logistics systems and networks. Clearly, for each of the different elements in the canvas, relevant input and information needs to be combined. In the case of a CDC, the value proposition is clear and involves a decoupling point into the city, stock location, etc. The customers who can make use of this service are very broad and involve many stakeholders in the supply chain: shippers, retailers, logistics service providers and consumers. The 
key resources could be clean transportation vehicles, or the CDC itself. The key activities are then closely related to the value proposition: offer a stock point, fast delivery towards the end receiver, etc. The canvas also shows the need for a good business case where revenues exceed costs. Especially in city logistics systems, this is not so easy to establish in practice. Clearly, the costs are more or less easily to determine, but it is not clear who is willing to pay for the services offered. Additionally, the revenue stream is guaranteed if enough volume is handled, which is especially not the case in the startup phase (hence the subsidizing of municipalities). These are key reasons why CDC setups find difficult ground in practice, and the sustainable business case is not easily reached.

Many stakeholders are involved with urban freight transport, each having their own, sometimes conflicting, stakes in urban freight transport. Specifically, authorities, carriers, receivers, residents, shippers and traffic participants all make use of the same scarce resources available in the urban areas. This makes it difficult to develop sustainable urban freight transport solutions, as a wide variety of (often conflicting) problem perceptions and solutions exist [6]. This, of course, has a significant impact on urban traffic and new sound logistics solutions are required to better manage the flow of goods into, through, and out of, urban areas. Urban goods transport thus emphasizes the need for a systemic view of the issues related to urban freight movements. An obvious list of stakeholders in city logistics, if rather traditional and myopic, are the service providers (e.g., shippers, carriers) and those receiving service (e.g., customers). A broader and a structural representation of the stakeholders is given in Anand et al. (2012), who initially classify them into two, being private actors and public authorities. According to the ontology they provide, shippers, carriers, receivers and private actors (namely B2B shippers, 3PL logistics providers, retailers and inhabitants) appear in the former category, whereas authorities at national, regional and local level are listed in the latter.

\section{Initiatives and New Concepts in City Logistics}

In order to take significant steps forward in urban logistics, new and out-of-the-box ideas are needed. Given new technology and real-time availability of information, it is possible to think ahead for new and challenging solutions and make a major leap forward. The literature is abundant with planning approaches, tools and techniques for freight transportation in general, and it is beyond the scope of this paper to review this broad area of research. The interest of this paper, however, is in concepts and methodologies that are specific to City Logistics applications, including those that are either inspired by or derived from it. This section first reviews some new initiatives in City Logistics, including some real-life implementations, followed by two new, albeit conceptual, ideas. 


\subsection{Initiatives}

City logistics in general, and urban freight transport in particular, has been receiving increasing attention over the recent years. As a consequence, a number of private and public sector initiatives have been proposed. An overview and a classification of these projects is presented in Benjelloun et al. (2009)). However, a limited amount of scientific research focused on the issue of better transportation management. Next to solutions initiated solely by (local) authorities and companies, there is a huge number of initiatives involving several stakeholders and combining two or all solution directions (i.e. technology, logistics and policy). These initiatives are system initiatives, since these initiatives require changes in more than one part of the urban freight transport system.

We observe three different system initiatives: the development and use of standard load units (e.g. city containers), the development and use of urban consolidation centers, and the development of underground logistics systems. The idea for a standard load-unit for city distribution is based on the success of the sea container. Standardized load unit initiatives are mainly an enabler for the success of other initiative types that depend on efficient transfer of goods, e.g. consolidation center initiatives. Urban consolidation centers are typical city logistics initiatives. The rationale for consolidation centers is to divide the freight transport in two parts: the part inside the city and the part outside the city. City Logistics models have been proposed in the academic literature. Most of these models mainly focused on passenger transport within urban areas. Modeling the demand of goods is important for urban transport. A number of demand models have been proposed for evaluating the demand for freight movements within urban areas (Rooijen en Quack, 2014).

It is safe to claim that the existing literature on City Logistics is at a consensus in seeing City Distribution Centers (CDCs) or Urban-freight Consolidation Centers (UCCs) lying at the heart of the overall concept. Some real-life implementations have been reported in the literature, which have indicated potential for success. For example, Browne et al. (2011)) describe an implementation of a micro-CDC in London where electric vans and tricycles are used as delivery vehicles for the last mile delivery. With the new system in place, significant reductions on total distance (by 20\%) and CO2equivalent emissions (by 54\%) are reported although the distance per parcel rose by $349 \%$. This substantial increase is due to the smaller capacity of delivery vehicles resulting in more delivery activity per day. The authors also report a $11 \%$ increase in the daytime road-space and time occupied by the vehicles per parcel within London, but there is a $10 \%$ reduction in the kerbside loading space and time for the same. Another initiative is described by Kikuta et al. (2012)) of a pilot implementation of an urban delivery system integrating the use of truck and the subway system in Japan. The system makes use of handcarts to transport the items on the subway. The authors have also conducted an Internet-based questionnaire and an on-board monitoring survey to gauge the views of the public on the new system. The results showed that there was support in general, 
although concerns were also expressed on safety and congestion in the subway due to the mixed transportation of people and cargo. Other examples can be found in Quak, who describes a total of 106 unique Urban Freight Transport Initiatives undertaken between 1998 and 2006.

\subsection{Cargo hitching}

Combining people and freight flows creates attractive business opportunities because the same transportation needs can be met with fewer vehicles and drivers. This can make socially desirable transport options economically viable in rural areas where the population is declining. In urban areas it reduces congestion and air pollution and facilitates the introduction of electric vehicles. A such, integrated people and freight synchromodal transportation networks are designed and the related coordination, planning and scheduling policies to enable efficient and reliable delivery of both persons and freight is managed. Think of combining different people based modalities, i.e. underground systems and use of public transport (rail, bus, subway) with freight volumes.

The paper by Ghilas et al. (2014) seeks an integrated solution for the transportation of passenger and freight simultaneously, so that fewer vehicles are required. The newly introduced problem concerns scheduling a set of vehicles to serve the requests such that a part of the journey can be carried out on a scheduled passenger transportation service. We propose an arc-based mixed integer programming formulation for the integrated transportation system. Computational results on a set of instances provide a clear understanding on the benefits of integrating passenger and freight transportation in the current networks, considering multi-modality of traditional passenger-oriented transportation modes, such as taxi, bus, train or tram. The authors particularly investigate the opportunity to make use of available public transportation as a part of the freight journey, which operates according to predetermined routes and schedules. Generally during off-peak hours, the capacity utilisation of fixed scheduled line (FSL) vehicles is relatively low. Transferring freight requests to fixed scheduled lines could then be beneficial for the whole transportation system. Therefore, such a request can be picked up by a pickup and delivery (PD) vehicle and transported to a station-hub, which is assumed to be located nearby. From there, the request continues its journey on a scheduled public transportation system. Afterwards, the same request can be picked up again by another $\mathrm{PD}$ vehicle to be delivered to its destination point.

Li et al. (2014) consider conceptual and mathematical models in which people and parcels are (simultaneously) handled by the same taxi network. From a city perspective, this system has the potential to alleviate urban congestion and environmental pollution. From a company perspective, new benefits are considered from the parcel transportation and costs are reduced for the actual parcel delivery, as no additional network needs to be set up to handle parcel requests. We propose two multi-commodity (people and parcels) 
sharing models. The Share-a-Ride Problem (SARP) is discussed and defined in detail. Specifically, for a set of people and parcel requests, the best schedules and routes are determined. A reduced problem based on the SARP, denoted as the Freight Insertion Problem (FIP), starts from a given route for handling people requests and inserts parcel requests into this route. The authors present MILP formulations for both problems and perform a numerical study. Scenarios addressed for FIP include both static and dynamic situations. The obtained numerical results provide valuable information for implementing a taxi sharing service.

\subsection{Physical internet}

The Physical Internet (PI, $\pi$ ) is a new concept for freight transportation and logistics aiming to improve the economic, environmental and societal efficiency and sustainability of the way physical objects are moved, stored, realized, supplied and used all across the world (Ballot et al., 2014; Montreuil, 2011; Physical Internet Initiative, 2015). Similarly to the City Logistics and digital internet concepts, the movements of freight in the PI are independent of the actual operations of the transportation and terminal handling and storage infrastructure and services, and proceed in an openly consolidated way through a series of carrier services and relay facilities. Freight is thus transported, handled and stored through a network of networks, a Logistics Web. Freight is encapsulated into $\pi$-containers, which are designed for logistics operations, and are standard, smart, green, modular, and reusable. $\pi$-containers are standardized worldwide in terms of dimensions, from the size of small cases up to that of cargo containers, functions and fixtures. They are routed through the Logistics Web by exploiting their real-time identification and communication capabilities combined to advanced service planning and dynamic routing methods.

Current logistics is dominated by a combination of point-to-point and hub-and-spoke transport. Even though these two ways are feasible in the PI, the dominance shifts to distributed multi-segment intermodal transport and shared facilities for product production, warehousing and distribution. A fundamental aim when conceptualizing and implementing the Physical Internet is universal interconnectivity, from the facility to the worldwide level, as well as for cities and urban regions. This transposes in a quest for high-performance transportation services and logistics centers, systems and movers, as well as innovative business, planning and management methods and software tools, for improving the performance of the participating stakeholders - producers, shippers, carriers, etc. -, that perceived by the customers, and the overall performance of the Physical Internet. The PI concept is gaining momentum in both research and applications, and has already shown significant potential gains in interurban transport and logistics (Ballot et al., 2014; Sarraj et al., 2014).

City Logistics and the Physical Internet share several key concepts, e.g., cooperation, 
consolidation, and the separation of commercial transaction generating the demand for transportation and the actual logistics and transport activities. They are also complimentary as City Logistics corresponds to the first and last segments of the worldwide Logistics Web. The Physical Internet can help further structure and empower sustainable city logistics networks, helping to efficiently getting products into, through and out of cities while minimizing negative impacts on citizens quality of life related to freight logistics such as pollution, noise, traffic and safety issues. Crainic and Montreuil (2015) examine this new Interconnected City Logistics idea and identify nine core concepts defining it.

\section{Conclusions and Vision}

This chapter has presented a systematic view of City Logistics by introducing the main components, along with some of the advances made in the literature with a particular focus on planning, designing and evaluating City Logistics systems. Initiatives are being taken by both public and private sectors, which, however either rely on the use of new technologies (e.g., electric vehicles) or environmentally-friendly modes of transport (e.g., tricycles). More, however, needs to be done. We identify three areas for exploration and further research, differentiated with respect to the type and nature of the work to be undertaken, namely, planning, technology and infrastructure:

- Planning: The state-of-the-art in the field is such that the existing research does not entirely and necessarily go hand-in-hand with the practical initiatives and implementations. At this point, it is worth comparing City Logistics with the traditional urban transportation systems studied in the extant literature. There is a long and distinguished research area in the latter case, which yielded many significant theoretical contributions, as well as advanced decision-support systems and software packages used by most cities and regional authorities around the world (see, e.g., Cascetta, 2001; Crainic and Florian, 2008; Florian, 2008; Florian and Hearn, 1995). Historically, the focus of these studies was on the demand for transportation by individual means, that is, by car, and the ability of the underlying transportation

systems of the cities to answer this demand. Later, their scope was broadened to encompass the public transport and alternative transportation modes, e.g., walking and bicycles. However, within the broader framework of City Logistics, such models will only address the passenger side of planning, which would (and should) constitute only a part of the broader picture. The other part should account for the increasingly significant freight activities that now take place in urban areas. Indeed, there does not yet exist a methodology integrating the individual and public transportation modes into a single model. This one aspect, which is unique to a setting such as City Logistics, is one that differentiates the field from others, and one which deserves attention from the scientific community. Our brief review of 
the literature shows that only very few planning models have so far been proposed specifically for City Logistics in the existing literature, and this constitutes one of the major challenges in the future of the field. It is even more remarkable that all methods and systems proposed do not address the matter of freight movements on the urban transportation system, except as simple approximations of base volumes on the arcs of the networks representing the streets and arteries of the city. One of the major challenges for the field is thus not only to develop the appropriate methods and tools for City Logistics system evaluation, but also to create the models and methods able to integrate individual, public and freight transportation into a comprehensive formulation.

- Technology: The use of various new technologies are already being suggested, and in some instances, implemented (see, e.g., Browne et al. (2011)) within City Logistics, with the primary motivation being the reduction of emissions and for a more environmentally friendly way of transportation operations. However, the initiatives are still at a micro-level and their integration with the existing and more traditional means of transport are yet to be looked into. Furthermore, the planning for such novel modes of transport, need to be either incorporated in the existing models and methodologies; alternatively, this will necessitate new planning tools to be able to respond to the requirements of the new technologies in an efficient way.

- Infrastructure: Whilst for well-established and heavily populated cities it might be difficult to undertake projects to design (or re-design) new transportation infrastructure for reasons of cost and land availability, amongst others, designing new cities from scratch, with an environmentally-friendly and integrated means of transportation is no longer an utopia. Indeed, there already exists two so-called "carbonzero" or "eco"-cities in the world (http://en.wikipedia.org/wiki/Zero-carbon_city), namely Masdar (UAE) and Dongtan (China), in which cars are banned within the city and transportation activities will be limited to the usage of electric vehicles, in some cases those that are on auto-pilot. It is recognized that new infrastructure comes with the expense of significant capital, but the benefits well may outweigh the initial set-up cost in the long run. The analysis and evaluation of such designs go beyond the traditional boundaries of Operations Research and Transportation Science, and requires input from disciplines such as engineering, architecture, economics and environmental planning, making the field of City Logistics all the more interdisciplinary and rich, and with exciting research prospects.

\section{Acknowledgments}

While working on this project, the second author was Adjunct Professor with the Department of Computer Science and Operations Research, Université de Montréal. Partial 
funding for this project has been provided by the Natural Sciences and Engineering Council of Canada (NSERC), through its Discovery Grants program. We also gratefully acknowledge the support of the Fonds de recherche du Québec through their infrastructure grants. 


\section{References}

G.-A. Ahrens. Sustainable Urban Transport Plans (SUTPs). Buletinul AGIR, An XIV (4):20-27, 2009.

C. Ambrosini and J.-L. Routhier. Objectives, Methods and Results of Surveys Carried out in the Field of Urban Freight Transport: An International Comparison. Transport Reviews, 24:55-77, 2004.

D. Ambrosino and M.G. Scutellà. Distribution Network Design: New Problems and Related Models. European Journal of Operational Research, 155(3):610-624, 2005.

N. Anand, M. Yang, J. Van Duin, and L. Tavasszy. Genclon: An ontology for city logistics. Expert Systems with Applications, 39(15):11944-11960, 2012.

J. Andersen, T.G. Crainic, and M. Christiansen. Service Network Design with Management and Coordination of Multiple Fleets. European Journal of Operational Research, 193(2):377-389, 2009a.

J. Andersen, T.G. Crainic, and M. Christiansen. Service Network Design with Asset Management: Formulations and Comparative Analyzes. Transportation Research Part C: New Technologies, 17(2):397-207, 2009b.

A. Balakrishnan, T.L. Magnanti, and P. Mirchandani. Network Design. In M. Dell'Amico, F. Maffioli, and S. Martello, editors, Annotated Bibliographies in Combinatorial Optimization, pages 311-334. John Wiley \& Sons, New York, NY, 1997.

M.M. Baldi, M. Ghirardi, G. Perboli, and R. Tadei. The capacitated transshipment locatin problem under uncertainty: A computational study. In E. Taniguchi and R. G. Thompson, editors, Seventh International Conference on City Logistics, June 7-11, 2011, Mallorca, Spain, volume 39 of Procedia - Social and Behavioral Sciences, pages 424-436. Elsevier, 2012.

E. Ballot, B. Montreuil, and R. D. Meller. The Physical Internet: The Network of Logistics Networks. La Documentation Franaise, Paris, France, 2014.

S. Balm, M. Browne, J. Leonardi, and H. Quak. Developing an evaluation framework for innovative urban and interurban freight transport solutions. Procedia-Social and Behavioral Sciences, 125:386-397, 2014.

J. Barceló, H. Grzybowska, and S. Pardo. Vehicle Routing and Scheduling Models, Simulation and City Logistics. In Zeimpekis, V., Tarantilis, C.D., Giaglis, G.M., and Minis, I., editors, Dynamic Fleet Management Concepts - Systems, Algorithms $\&$ Case Studies, pages 163-195. Springer, 2007.

J.M. Belenguer, E. Benavent, C. Prins, C. Prodhon, and R. Wolfler-Calvo. A Branchand-Cut Algorithm for the Capacitated Location Routing Problem. Computers 83 Operations Research, 38(6):931-941, 2010. 
A. Benjelloun and T.G. Crainic. Trends, Challenges, and Perspectives in City Logistics. In Transportation and Land Use Interaction, Proceedings TRANSLU'08, pages 269284. Editura Politecnica Press, Bucharest, Romania, 2008.

A. Benjelloun and T.G. Crainic. Trends, Challenges, and Perspectives in City Logistics. Buletinul AGIR, An XIV(4):45-51, 2009.

A. Benjelloun, T.G. Crainic, and Y. Bigras. Towards a Taxonomy of City Logistics Systems. In City Logistics VI: Proceedings of the 6th International Conference on City Logistics, Puerto Vallarta, Mexico, 30 June - 2 July, pages 409-421. Institute for City Logistics, Kyoto, Japan, 2009.

A. Bettinelli, T.G. Crainic, and D. Vigo. The Multi-Zone Multi-Trip Vehicle Routing Problem with Separate Delivry and Collection. Publication, Centre interuniversitaire de recherche sur les réseaux d'entreprise, la logistique et le transport, Université de Montréal, Montréal, QC, Canada, 2015. forthcoming.

M. Boccia, T.G. Crainic, A. Sforza, and C. Sterle. A Metaheuristic for a Two-Echelon Location-Routing Problem. In P. Festa, editor, Experimental Algorithms, volume 6049 of Lecture Notes in Computer Science / Programming and Software, pages 288-301. Springer-Verlag, Berlin Heidelberg, 2010.

M. Boccia, T.G. Crainic, A. Sforza, and C. Sterle. Location-Routing Models for Designing a Two-Echelon Freight Distribution System. Publication CIRRELT-2011-06, Centre interuniversitaire de recherche sur les réseaux d'entreprise, la logistique et le transport, Université de Montréal, Montréal, QC, Canada, 2011.

J. Boerkamps and A. van Binsbergen. GoodTrip - A New Approach for Modelling and Evaluating Urban Goods Distributrion. In Taniguchi, E. and Thompson, R.G., editors, City Logistics I, 1st International Conference on City Logistics, pages 175-186. Institute of Systems Science Research, Kyoto, 1999.

M. Browne, S. Allen, S. Andersen, and A. Woodburn. Urban Freight Consolidation Centres. In Taniguchi, E. and Thompson, R.G., editors, Recent Advances in City Logistics, pages 253-265. Elsevier, Amsterdam, 2006.

M. Browne, J. Allen, and J. Leonardi. Evaluating the use of an urban consolidation centre and electric vehicles in central london. IATSS research, 35(1):1-6, 2011.

Campbell, J.F. A Survey of Network Hub Location Problems. Studies in Locational Analysis, 6:31-49, 1994b.

E. Cascetta. Transportation Systems Engineering: Theory and Methods. Kluwer Academic Publishers, Dordrecht, The Netherlands, 2001.

C. Contardo, V. Hemmelmayr, and T. G. Crainic. Lower and upper bounds for the twoechelon capacitated location-routing problem. Computers \& Operations Research, 39 (12):3185-3199, 2012. 
C. Contardo, J.-F. Cordeau, and B. Gendron. A Computational Comparison of Flow Formulations for the Capacitated Location-Routing Problem. Discrete Optimization, 10(4):263-295, 2013.

T. Crainic, N. Ricciardi, and G. Storchi. The-Day-Before Planning for Advanced Freight Transportation Systems in Congested Urban Areas. Publication CRT-2005-19, Centre de recherche sur les transports, Université de Montréal, Montréal, QC, Canada, 2005.

T. G. Crainic, N. Ricciardi, and G. Storchi. Models for evaluating and planning city logistics systems. Transportation Science, 43(4):432-454, 2009a.

T. G. Crainic, G. Perboli, S. Mancini, and R. Tadei. Two-echelon vehicle routing problem: a satellite location analysis. Procedia - Social and Behavioral Sciences, 2(3):5944-5955, 2010 .

T. G. Crainic, F. Errico, W. Rei, and N. Ricciardi. Integrating c2e and c2c traffic into city logistics planning. Procedia-Social and Behavioral Sciences, 39:47-60, 2012a.

T.G. Crainic. Network Design in Freight Transportation. European Journal of Operational Research, 122(2):272-288, 2000.

T.G. Crainic. Long-Haul Freight Transportation. In Hall, R.W., editor, Handbook of Transportation Science, pages 451-516. Kluwer Academic Publishers, Norwell, MA, second edition, 2003.

T.G. Crainic and M. Florian. National Planning Models and Instruments. INFOR, 46 (4):81-90, 2008.

T.G. Crainic and K. Kim. Intermodal Transportation. In Barnhart, C. and Laporte, G., editors, Transportation, volume 14 of Handbooks in Operations Research and Management Science, chapter 8, pages 467-537. North-Holland, Amsterdam, 2007.

T.G. Crainic and B. Montreuil. Physical Internet Enabled Interconnected City Logistics. Publication, Centre interuniversitaire de recherche sur les réseaux d'entreprise, la logistique et le transport, Université de Montréal, Montréal, QC, Canada, 2015. forthcoming.

T.G. Crainic and A. Sgalambro. Service Network Design Models for Two-tier City Logistics. Optimization Letters, 8(4):1375-1387, 2014.

T.G. Crainic, N. Ricciardi, and G. Storchi. Advanced Freight Transportation Systems for Congested Urban Areas. Transportation Research Part C: Emerging Technologies, 12(2):119-137, 2004.

T.G. Crainic, N. Ricciardi, and G. Storchi. Models for Evaluating and Planning City Logistics Transportation Systems. Publication CIRRELT-2007-65, Centre interuniversitaire de recherche sur les réseaux d'entreprise, la logistique et le transport, Université de Montréal, Montréal, QC, Canada, 2007. 
T.G. Crainic, S. Mancini, G. Perboli, and R. Taddei. Clustering-Based Heuristics for the Two-Echelon Vehicle Routing Problem. Publication CIRRELT-2008-46, Centre interuniversitaire de recherche sur les réseaux d'entreprise, la logistique et le transport, Université de Montréal, Montréal, QC, Canada, 2008.

T.G. Crainic, G.C. Crisan, M. Gendreau, N. Lahrichi, and W. Rei. Multi-thread Integrative Cooperative Optimization for Rich Combinatorial Problems. In The 12th International Workshop on Nature Inspired Distributed Computing - NIDISC'09, 2529 May, Rome, 2009b. CD-ROM.

T.G. Crainic, N. Ricciardi, and G. Storchi. Models for Evaluating and Planning City Logistics Transportation Systems. Publication CIRRELT-2009-11, Centre interuniversitaire de recherche sur les réseaux d'entreprise, la logistique et le transport, Université de Montréal, Montréal, QC, Canada, 2009c.

T.G. Crainic, X. Fu, M. Gendreau, W. Rei, and S.W. Wallace. Progressive Hedging-based Meta-heuristics for Stochastic Network Design. Networks, 58(2):114-124, 2011a.

T.G. Crainic, S. Mancini, G. Perboli, and R. Tadei. Multi-Start Heuristics for the TwoEchelon Vehicle Routing Problem. In Merz, P. and Hao, J.-K., editors, Evolutionary Computation in Combinatorial Optimization - EvoCOP 2011, volume 6622 of Lecture Notes in Computer Science, pages 179-190. Springer-Verlag, Berlin Heidelberg, $2011 \mathrm{~b}$.

T.G. Crainic, A. Sforza, and C. Sterle. Location-Routing Models for Two-Echelon Freight Distribution System Design. Publication CIRRELT-2011-40, Centre interuniversitaire de recherche sur les réseaux d'entreprise, la logistique et le transport, Université de Montréal, Montréal, QC, Canada, 2011c.

T.G. Crainic, S. Mancini, G. Perboli, and R. Tadei. Impact of Generalized Travel Costs on Satellite Location in Two-echelon VRP. In E. Taniguchi and R. G. Thompson, editors, Seventh International Conference on City Logistics, June 7-11, 2011, Mallorca, Spain, volume 39 of Procedia - Social and Behavioral Sciences, pages 195-204. Elsevier, 2012b.

T.G. Crainic, M. Hewitt, M. Toulouse, and D.M.. Vu. Service Network Design with Resource Constraints. Transportation Science, 2014. on line //dx.doi.org/10.1287/trsc.2014.0525.

T.G. Crainic, F. Errico, W. Rei, and N. Ricciardi. Modeling Demand Uncertainty in Two-Tiered City Logistics Planning. Transportation Science, 2015. To appear.

Daskin, M.S. Network and Discrete Location. Models, Algorithms, and Applications. John Wiley \& Sons, New York, NY, 1995.

R. De Souza, M. Goh, H.-C. Lau, W.-S. Ng, and P.-S. Tan. Collaborative urban logistics synchronizing the last mile, a singapore research perspective. Procedia-Social and Behavioral Sciences, 125:422-431, 2014. 
D. Diziain, E. Taniguchi, and L. Dablanc. Urban logistics by rail and waterways in france and japan. Procedia-Social and Behavioral Sciences, 125:159-170, 2014.

R. Dondo and J. Cerdá. A cluster-based optimization approach for the multi-depot heterogeneous fleet vehicle routing problem with time windows. European Journal of Operational Research, 176(3):1478-1507, 2007.

M. Drexl and M. Schneider. A Survey of the Standard Location-Routing Problem. Working paper lpis-03/2014, Johannes Gutenberg University, Mainz, Germany, 2014.

M. Drexl and M. Schneider. A Survey of Variants and Extentions of the Location-Routing Problem. European Journal of Operational Research, 241(2):283-308, 2015.

Z. Drezner, editor. Facility Location. A Survey of Applications and Methods. SpringerVerlag, New York, NY, 1995.

Z. Drezner and H. Hamacher, editors. Facility Location: Application and Theory. Springer Verlag, Berlin, 2002.

R. Ducret and L. . Delatre. Parcel delivery and urban logistics - changes in urban courier, express and parcel services: the French case. In 13th World Conference on Transport Research, July 15-18, 2013 - Rio de Janeiro, Brazil, 2013. https://halshs.archivesouvertes.fr/halshs-00853932, Accessed December 302014.

J.F. Ehmke, editor. Integration of information and optimization models for routing in city logistics. Springer, 2012.

M. Florian. Models and Software for Urban and Regional Transportation Planning: The Contribution of the Center for Research on Transportation. INFOR, 46(1):29-50, 2008.

M. Florian and D. Hearn. Network Equilibrium Models and Algorithms. In M. Ball, Magnanti, T.L., Monma, C.L., and Nemhauser, G.L., editors, Network Routing, volume 8 of Handbooks in Operations Research and Management Science, pages 485-550. North-Holland, Amsterdam, 1995.

M. Florian, M. Mahut, and N. Tremblay. Application of a Simulation-Based Dynamic Traffic Assignment Model. European Journal of Operational Research, 189(3):13811392, 2008.

M. Friedrich, T. Haupt, and K. Nökel. Freight Modelling: Data Issues, Survey Methods, Demand and Network Models. presented at the 10th International Conference on Travel Behaviour Research, Lucerne, 2003.

G. Gentile and D. Vigo. Movement Generation and Trip Distribution for Freight Demand Modelling Applied to City Logistics. Technical report, Università di Bologna, Italy, 2007. 
P. Gianessi. Solving Strategic and Tactical Optimization Problems in City Logistics. PhD thesis, Université Paris 13, France, 2014.

P. Gianessi, L. Alfandari, L. Létocart, and R. Wolfler-Calvo. The multicommodity-ring location routing problem. Transportation Science, 2015. to appear.

J. Gonzalez-Feliu, F. Semet, and J.-L. Routhier, editors. Sustainable Urban Logistics: Concepts, Methods and Information Systems. Springer, 2014.

S. Gragnani, G. Valenti, and M.P. Valentini. City Logistics in Italy: A National Project. In Taniguchi, E. and Thompson, R.G., editors, Logistics Systems for Sustainable Cities, pages 279-293. Elsevier, Amsterdam, 2004.

M. Grötschel, C. Monma, and M. Stoer. Design of Survivable Networks. In M. Ball, T. Magnanti, C. Monma, and G. Nemhauser, editors, Network Models, volume 7 of Handbooks in Operations Research and Management Science, pages 617-672. NorthHolland, Amsterdam, 1995.

O. Guyon, N. Absi, D. Feillet, and T. Garaix. A Modeling Approach for Locating Logistics Platforms for Fast Parcels Delivery in Urban Areas. In E. Taniguchi and R. G. Thompson, editors, Seventh International Conference on City Logistics, June 7-11, 2011, Mallorca, Spain, volume 39 of Procedia - Social and Behavioral Sciences, pages 360-368. Elsevier, 2012.

V. C. Hemmelmayr, J.-F. Cordeau, and T. G. Crainic. An adaptive large neighborhood search heuristic for two-echelon vehicle routing problems arising in city logistics. Computers $\&$ operations research, 39(12):3215-3228, 2012.

J. Holguín-Veras and G.R. Patil. A multicommodity integrated freight origin-destination synthesis model. Networks and Spatial Economics, 8(2):309-326, 2008.

J. Holguín-Veras and E. Thorson. Modeling commercial vehicle empty trips with a first order trip chain model. Transportation Research Part B: Methodological, 37(2):129$148,2003$.

A. Huart. Optimization of multi-modeal transportation chains in city logistics / Optimisation de ressources en logistique urbainel. PhD thesis, Université de Valenciennes et du Hainaut-Cambrésis, France, 2011.

B.J.P. Janssen and A.H. Oldenburger. Product Channel Logistics and City Distribution Centers; The case of the Netherlands. In OECD Seminar on Future Road Transport Systems and Infrastructures in Urban Areas, pages 289-302, Chiba, 1991.

J. Kikuta, T. Ito, I. Tomiyama, S. Yamamoto, and T. Yamada. New subway-integrated city logistics system. Procedia - Social and Behavioral Sciences, 39:476-489, 2012.

A.J. King and S.W.. Wallace. Modeling with Stochastic Programming. Springer, New York, 2012. 
Klose, A. and Drexl, A. Facility Location Models for Distribution System Design. European Journal of Operational Research, 1622(1):4-29, 2005.

U. Kohler. An Innovating Concept for City-Logistics. In Proceedings 4th World Congress on Intelligent Transportat Systems, Berlin (CD ROM), 1997.

U. Kohler. How to Change Urban Traffic with City Logistics. In Schnieder, E. and Becker, U., editors, Control in Transportation Systems 2000 - Proceedings 9th IFAC Symposium, Braunschweig, Germany, volume 1, pages 199-201. Pergamon, Oxford, 2001.

Labbé, M., Peeters, D., and Thisse, J.-F. Location on Networks. In M. Ball, Magnanti, T.L., Monma, C.L., and Nemhauser, G.L., editors, Network Routing, volume 8 of Handbooks in Operations Research and Management Science, pages 551-624. NorthHolland, Amsterdam, 1995.

N. Lahrichi, T.G. Crainic, M. Gendreau, W. Rei, C.C. Crisan, and V. Thuibaut. An Integrative Cooperative Search Framework for Multi-Decision-Attribute Combinatorial Optimization. European Journal of Operational Research, 2015. forthcoming.

G. Laporte. Location-Routing Problems. In Golden, B.L. and Assad, A.A., editors, Vehicle Routing: Methods and Studies, pages 163-197. North-Holland, Amsterdam, 1988.

A.-G. Lium, T.G. Crainic, and S.W. Wallace. A Study of Demand Stochasticity in Service Network Design. Transportation Science, 43(2):144-157, 2009.

T.L. Magnanti and R. Wong. Network Design and Transportation Planning: Models and Algorithms. Transportation Science, 18(1):1-55, 1984.

H.S. Mahmassani. Dynamic Network Traffic Assignment and Simulation Methodology for Advanced System Management Applicationsl. Networks and Spatial Economics, 1 (3-4):267-292, 2001.

H.S. Mahmassani and K.F. Abdelghany. DYNASMART-IP: Dynamic traffic assignment meso-simulator for intermodal networks. In Lam, W.H.K. and Bell, M.G.H., editor, Advanced Modeling for Transit Operations and Service Planning, pages 201-230. Emerald, Bingley, UK, 2003.

M. Mahut, M. Florian, P. Tremblay, M. Campbell, D. Patman, and u. McDaniel. Calibration and Application of a Simulation Based Dynamic Traffic Assignment Model. Transportation Research Record, 1876:101-111, 2004.

S. Mancini, J. Gonzalez-Feliu, and T.G. Crainic. Planning and Optimization Methods for Advanced Urban Logistics Systems at Tactical Level. In J. Gonzalez-Feliu, F. Semet, and J.-L. Routhier, editors, Sustainable Urban Logistics: Concepts, Methods and Information Systems, pages 145-164. Springer, 2014. 
R. Masson, A. Trentini, F. Lehuédé, N. Malhéné, O. Péton, and H. Tlahig. Optimization of a city logistics transportation system with mixed passengers and goods. EURO Journal on Transportation and Logistics, 2015. to appear.

Meimbresse, B. and Sonntag, H. Modelling Urban Commercial Traffic with the Model WIVER. In D. Patier-Marque, editor, L'intégration des marchandises dans le système des déplacements urbains - Actes des Treizièmes Entretiens Jacques Cartier, Montréal, octobre 2000, volume 15 of Études et recherches. Laboratoire d'Économie des Transports, Lyon, France, 2001.

H. Mina, V. Jayaraman, and R. Srivastava. Combined Location-routing Problems: A Synthesis and Future Research Directions. European Journal of Operations Research, 108(1):1-15, 1998.

Mirchandani, P.S. and Francis, R.L., editors. Discrete Location Theory. John Wiley \& Sons, New York, NY, 1990.

B. Montreuil. Towards a Physical Internet: Meeting the Global Logistics Sustainability Grand Challenge. Logistics Research, 3(2-3):71-87, 2011.

B. Montreuil, E. Ballot, and W. Tremblay. Structural Modular Design of Physical Internet Containers. In Progress in Material Handling Research, volume 13. MHI, Charlotte, NC, USA, 2015. to appear.

P.K. Nguyen, T.G. Crainic, and M. Toulouse. A Tabu Search for Time-dependent MultiZone Multi-Trip Vehicle Routing Problem with Time Windows. European Journal of Operational Research, 231(1):43-56, 2013.

P.K. Nguyen, T.G. Crainic, and M. Toulouse. Synchronized Multi-Trip Multi-Traffic Pickup and Delivery in City Logistics. Publication CIRRELT-2015-05, Centre interuniversitaire de recherche sur les réseaux d'entreprise, la logistique et le transport, Université de Montréal, Montréal, QC, Canada, 2015a.

P.K. Nguyen, T.G. Crainic, and M. Toulouse. Multi-Trip Pickup and Delivery Problem with Time Windows and Synchronization. Publication CIRRELT-2015-41, Centre interuniversitaire de recherche sur les réseaux d'entreprise, la logistique et le transport, Université de Montréal, Montréal, QC, Canada, 2015b. forthcoming.

A. Nuzzolo and A. Comi. City logistics planning: Demand modelling requirements for direct effect forecasting. Procedia - Social and Behavioral Sciences, 125:239-250, 2014a.

A. Nuzzolo and A. Comi. Urban freight demand forecasting: a mixed quantity/delivery/vehicle-based model. Transportation Research Part E: Logistics and Transportation Review, 65:84-98, 2014b.

R. Ooishi and E. Taniguchi. Effects and Profitability of Constructing the New Underground Freight Transport System. In Taniguchi, E. and Thompson, R.G., editors, City 
Logistics I, 1st International Conference on City Logistics, pages 303-316. Institute of Systems Science Research, Kyoto, 1999.

D. Patier. La logistique dans la ville. CELSE Editeur, Paris, France, 2002.

M.B. Pedersen, T.G. Crainic, and O.B.G. Madsen. Models and Tabu Search Metaheuristics for Service Network Design with Asset-Balance Requirements. Transportation Science, 43(2):158-177, 2009.

G. Perboli, R. Tadei, and D. Vigo. The two-echelon capacitated vehicle routing problem: models and math-based heuristics. Transportation Science, 45(3):364-380, 2011.

Physical Internet Initiative. www.physicalinternetinitiative.org, 2015.

W.B. Powell. Dynamic Models of Transportation Operations. In Graves, S. and de Kok, A.G., editors, Supply Chain Management, volume 11 of Handbooks in Operations Research and Management Science, pages 677-756. North-Holland, Amsterdam, 2003.

W.B. Powell. Approximate Dynamic Programming. John Wiley and Sons, 2nd edition, 2011.

W.B. Powell, B. Bouzaïene-Ayari, and H.P. Simaõ. Dynamic Models for Freight Transportation. In Barnhart, C. and Laporte, G., editors, Transportation, volume 14 of Handbooks in Operations Research and Management Science, pages 285-365. NorthHolland, Amsterdam, 2007.

C. Prins, C. Prodhon, and R. Wolfler-Calvo. A memetic algorithm with population management (majpm) for the capacitated location-routing problem. In M. B. et al., editor, Evolutionary Computation in Combinatorial Optimisation, volume 3906 of Lecture Notes in Computer Science, pages 183-194. Springer-Verlag, New York, NY, USA, 2006.

C. Prodhon and C. Prins. A Survey of Recent Research on Location-Routing Problems. European JOurnal of Operational Research, 238(1):1-17, 2014.

H. Quak. Sustainability of Urban Freight Transport: Retail Distribution and Local Regulations in Cities. PhD thesis, Rotterdam Erasmus University., 2008.

ReVelle, C.S. and Eiselt H.A. Location Analysis: A Synthesis and Survey. European Journal of Operational Research, 165(1):1-19, 2005.

W. Ruske. City Logistics - Solutions for Urban Commercial Transport by Cooperative Operations Management. In OECD Seminar on Advanced Road Transport Technologies, Omiya, Japan, 1994.

R. Sarraj, E. Ballot, S. Pan, D. Hakimi, and B. Montreuil. Interconnected Logistics Networks and Protocols: Simulation-based Efficiency Assessment. International Journal of Production Research, 52(11):3185-3208, 2014. 
C. Sterle. Location-Routing Models and Methods for Freight Distribution and Infomobility in City Logistics. PhD thesis, Universitá degli Studi di Napoli "Federico II", Italy, 2009.

D. Tamagawa, E. Taniguchi, and T. Yamada. Evaluating city logistics measure using multi-agent model. Procedia - Social and Behavioral Sciences, 2:6001-6012, 2010.

E. Taniguchi. Concepts of city logistics for sustainable and liveable cities. Procedia-Social and Behavioral Sciences, 151:310-151, 2014.

E. Taniguchi and R.G. Thompson. Modeling City Logistics. Transportation Research Record, 1790:45-51, 2002.

E. Taniguchi and R.E.C.M. van der Heijden. An Evaluation Methodology for City Logistics. Transport Reviews, 20(1):65-90, 2000.

E. Taniguchi, T. Noritake, T. Yamada, and T. Izumitani. Optimal Size and Location Planning of Public Logistics Terminals. Transportation Research E, 35(3):207-222, 1999.

E. Taniguchi, S. Kawakatsu, and H. Tsuji. New Co-Operative System Using Electric Vans for Urban Freight Transport. In Sucharov, L.J. and Brebbia, C.A., editors, Urban Transport and the Environment for the 21st Century VI, pages 201-210. WIT Press, Southampton, 2000.

E. Taniguchi, R.G. Thompson, T. Yamada, and J.H.R. van Duin. City Logistics: Network Modelling and Intelligent Transport Systems. Pergamon, Amsterdam, 2001a.

E. Taniguchi, T. Yamada, and M. Tamaishi. Dynamic Vehicle Routing and Scheduling with Real Time Informations. In Taniguchi, E. and Thompson, R.G., editors, City Logistics II, Second International Conference on City Logistics, pages 111-125. Institute of Systems Science Research, Kyoto, 2001b.

R.G. Thompson. Intelligent Vehicle Routing and Scheduling. In Taniguchi, E. and Thompson, R.G., editors, Logistics Systems for Sustainable Cities, pages 97-109. Elsevier, Amsterdam, 2004.

R.G. Thompson and E. Taniguchi. City Logistics and Transportation. In Handbook of Logistics and Supply-Chain Management, pages 393-405. Elsevier, Amsterdam, 2001.

P. Toth and D. Vigo. Vehicle Routing: Problems, Methods, and Applications, volume 18. SIAM, 2014.

J.H.R. van Duin. Evaluation and Evolution of the City Distribution Concept. In Urban Transport and the Environment for the 21st Century III, pages 327-337. WIT Press, Southampton, 1997. 
J.H.R. van Duin. Simulation of Underground Freight Transport Systems. In Urban Transport and the Environment for the 21st Century IV, pages 149-158. WIT Press, Southampton, 1998.

J.H.R. van Duin. Urban logistics by rail and waterways in france and japanecity logistics through the canals? a simulation study on freight waterborne transport in the innercity of amsterdam. International Journal of Urban Sciences, 18(2):186-200, 2013.

J.H.R. van Duin, A. Klock, N. Anand, L. Tavasszy, and E. Taniguchi. Towards an agentbased modelling approach for the evaluation of dynamic usage of urban distribution centres. Procedia - Social and Behavioral Sciences, 39:333-348, 2012.

T. Van Rooijen and H. Quak. City logistics in the european civitas initiative. ProcediaSocial and Behavioral Sciences, 125:312-325, 2014.

J. Visser, A. van Binsbergen, and T. Nemoto. Urban Freight Transport Policy and Planning. In Taniguchi, E. and Thompson, R.G., editors, City Logistics I, 1st International Conference on City Logistics, pages 39-69. Institute of Systems Science Research, Kyoto, 1999.

J. Visser, T. Nemoto, and M. Browne. Home delivery and the impacts on urban freight transport: A review. Procedia-Social and Behavioral Sciences, 125:15-27, 2014.

O. Wangapisit, E. Taniguchi, J.S.E. Teo, and A.. Qureshi. Multi-agent systems modelling for evaluating joint delivery systems. Procedia - Social and Behavioral Sciences, 125: 472-483, 2014. 